\title{
Rupestrian World Heritage Sites: Instability Investigation and Sustainable Mitigation
}

\author{
Claudio Margottini, Peter Bobrowsky, Giovanni Gigli, Heinz Ruther, \\ Daniele Spizzichino, and Jan Vlcko
}

\begin{abstract}
Rupestrian settlements were among the first man-made works in the history of humanity. The most relevant masterpieces of such human history have been included in the UNESCO World Heritage List. These sites and their associated remains are not always in equilibrium with the environment. They are continuously impacted and weathered by a variety of internal and external factors, both natural and human-induced, with rapid and/or slow onset. These include major sudden natural hazards, such as earthquakes or extreme meteorological events, but also slow cumulative processes such as the erosion of rocks, compounded by the effects of climate change, as well as the role of humans, especially in conflict situations. Many rupestrian sites have been carved into soft rock, generally with UCS $<25 \mathrm{MPa}$ (ISRM in Int J Rock Mech Min Sci Geomech Abs 18:85-110, 1981), in vertical cliffs, and show major conservation issues in the domain of rock slope stability and rock weathering. This paper reports the experience of rock fall mitigation in rupestrian sites, mainly from the UNESCO World Heritage List (Bamiyan in Afghanistan; Lalibela in Ethiopia; Petra in Jordan, Vardzia in Georgia and others). The general approach, implemented in the activities, includes a very detailed interdisciplinary study, with the objective to understand degradation processes and causative factors, followed, as a subsequent step, by proper field conservation work. The latter is mainly related to re-discovering and potential application of traditional knowledge and sustainable practices, and is primarily based on local conservation techniques.
\end{abstract}

\section{Keywords}

Rupestrian site - Geotechnical threats - Investigations • Monitoring • Sustainable conservation policies

C. Margottini $(\bowtie) \cdot$ D. Spizzichino

Department of Geological Survey of Italy, ISPRA, via Brancati, 60, 00143 Rome, Italy

e-mail: claudio.margottini@isprambiente.it

D. Spizzichino

e-mail: daniele.spizzichino@isprambiente.it

P. Bobrowsky

Geological Survey of Canada, Natural Resources Canada, 9860

West Saanich Road, 6000Sidney, BC V8L 4B2, Canada

e-mail: Peter.Bobrowsky@ canada.ca

\section{G. Gigli}

University of Florence, Department of Earth Sciences,

Largo E.Fermi, 2, 50125 Florence, Italy

e-mail: giovanni.gigli@unifi.it

\section{H. Ruther}

Principal Investigator "African Cultural Heritage Sites and Landscapes" Project Zamani Project Division of Geomatics (APG), University of Cape Town, 7701 Private Bag, Rondebosch, South Africa

e-mail: heinz.ruther@zamaniproject.org

J. Vlcko

Department of Engineering Geology, Faculty of Natural Sciences, Comenius University, Bratislava Ilkovicova 6, Mlynska Dolina, Slovakia

e-mail: vlcko@fns.uniba.sk 


\section{Introduction}

Rupestrian settlements were among the first man-made works in the history of humanity. During some 3 million years, humankind survival relied on two basic activities: hunting (or fishing) and gathering edible items (from plants to insects). A radical change came roughly 10,000 years ago, after the last glacial age, when people first learned to cultivate crops and to domesticate animals, in what can certainly be considered one of the most significant developments in human history (Margottini and Spizzichino 2014).

A subsequent significant change concerned the process of planning, designing and building structures for human settlements. Architectural works, in the material form of buildings and/or rupestrian settlements, are often perceived as cultural symbols and as works of art, and civilizations are often identified by their architectural achievements. However, architectural works are not merely entities of physical construction. They represent the synthesis of a complex system that, throughout time, has been guided by human genius, and depends on the availability and types of construction materials (natural geological resources). Their form is determined by social and economic conditions, by local morphological situations (e.g. defensive settlements on top of cliff), and is influenced by local meteo-climatic conditions.

The most relevant masterpieces of such human history have been included in the UNESCO World Heritage List.

\section{Major Threats Affecting Rupestrian Sites}

The sites and remains discussed herein have not always been in equilibrium with the environment. They are continuously impacted and degraded by several internal and external factors, both natural and human-induced, with rapid and/or slow onset. These include major sudden natural hazards, such as earthquakes or extreme meteorological events, but also slow, cumulative processes such the erosion of rocks, compounded by the effects of climate change, including the role of humans, especially in conflict situations.

Many rupestrian sites have been carved into soft rock, generally with UCS < $25 \mathrm{MPa}$ (ISRM, 1981), in vertical cliffs and show major conservation issues in the domain of rock slope stability and rock weathering. The low strength range of rock might be influenced by physical characteristics, such as size, saturation degree, weathering and mineral content. Finally, the investigations generally show that the strength reduces significantly with saturation (Agustawijaya 2007).

The low strength of the rock, together with the discontinuity pattern in steep slopes and the weakening of the cliff produced by the man-made settlements, pose a serious concern for the long term stability of the sites.
As a confirmation, the following Fig. 1 shows the relationship between UCS and porosity for some rupestrian sites discussed in this paper. It is evident that the low UCS value is generally coupled with high porosity, especially in volcanic materials (Lalibela and Vardzia). On the other hand, the continental/sedimentary geological formations of Bamiyan and Petra exhibit a relevant vertical heterogeneity, so values reported here are rough estimates.

Here we report on some advances developed during rock fall and weathering analysis, monitoring and mitigation in rupestrian sites, mainly belonging to the UNESCO world heritage list (Bamiyan in Afghanistan; Lalibela in Ethiopia; Petra in Jordan and Vardzia in Georgia) and under UNESCO coordination. The general approach, implemented in the conservation activities, include a very detailed interdisciplinary study, to understand rock degradation processes and causative factors, followed by field conservation work. The latter is mainly related to re-discovering traditional knowledge and sustainable practices and is based on the application of local conservation techniques (Margottini et al. 2016a, b).

The described methodology is then primarily aimed at the protection of the heritage sites but, at the same time and when possible, at the empowerment of local communities to independently manage the site. Protecting heritage from natural threats is, in fact, not a luxury but a fundamental step to be given priority together with other humanitarian concerns. This is especially relevant at a time when traditional knowledge and sustainable practices, which ensured a certain level of protection from the worst effects of natural hazards or human-made disasters, are being progressively abandoned and/or forgotten (Margottini et al. 2016a, b).

Following is a brief description of some advanced techniques employed by the authors and sustainable conservation practices in selected case histories.

\section{Investigation Techniques}

\section{Laser Scanner}

As a result of the outstanding development of terrestrial laser scanner (TLS) in recent years, rock slopes and rupestrian settlements can now be investigated and mapped through high resolution point clouds.

Laser scanning for the generation of surface models acquires $3 \mathrm{D}$ surface information by determining the $\mathrm{xyz}$ co-ordinates of large numbers of surface points, referred to as a point cloud. The scanner (Fig. 2) can only measure and record surfaces in the field-of-view of the instrument and it is therefore necessary to move the instrument to multiple positions to cover an entire object. The scans obtained in this way, must overlap each other sequentially to allow the 
Fig. 1 The relationship between Uniaxial compressive strength and porosity for some of the case studies discussed in this paper

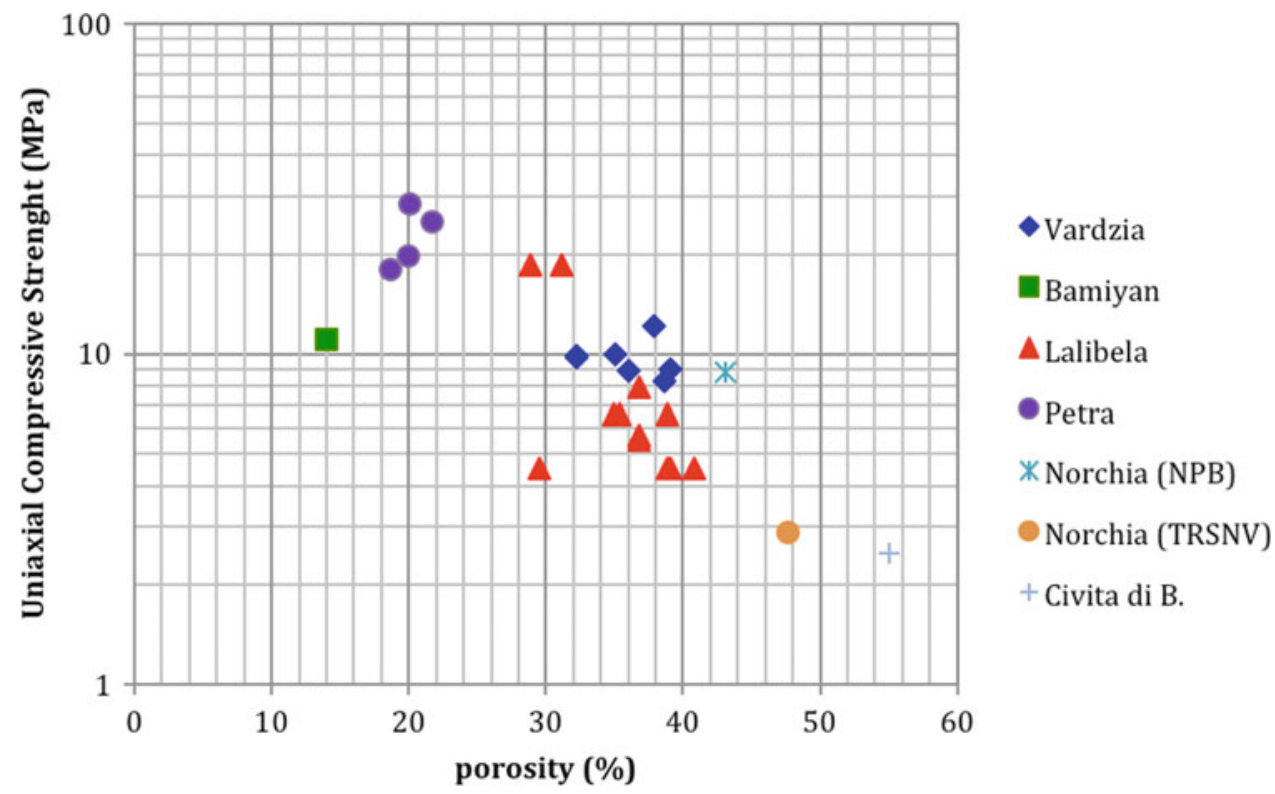

combination of all acquired scans into a single point cloud. In subsequent processing the individual points are connected to form a triangulated mesh which can be further processed to create a complete, full surface. Finally, photos can be draped over the surface to create a photo-realistic appearance. The interval between points of the point cloud, referred to as resolution, can be chosen by the operator of the laser scanner depending on the required detail and the complexity of the surface.

Finally, TLS can also be utilised to identify the different members of a stratigraphic sequence. In fact, the instrument records the RGB values and measures the reflected ray energy, providing the reflectivity index $\mathrm{I}$ of the micro-portion surface (Ercoli et al. 2013). Therefore, the reflectivity index associated with each TLS point can provide an indirect estimation of the lithothypes (Fig. 3). Intensity variations as a result of different angles of incident proved insignificant in this context.

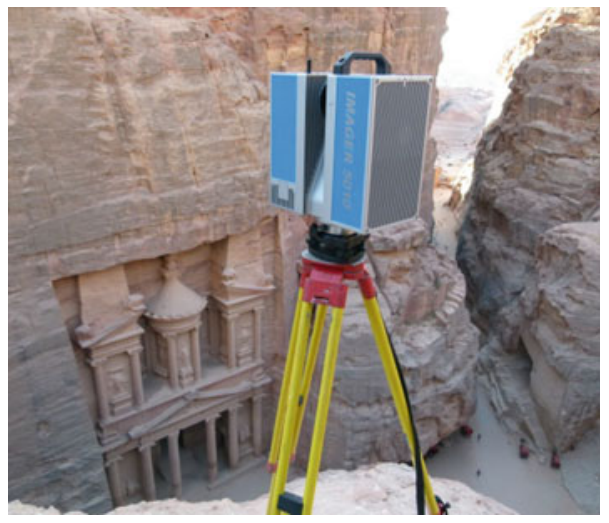

Fig. 2 Laser scanner (Z\&F) above Al Khazneh (Petra, Jordan)

\section{The Siq of Petra}

The Siq, the main entrance to the Nabatean archaeological site of Petra (Jordan), is a $1.2 \mathrm{~km}$ long, naturally formed gorge, with an irregular horizontal shape and a complex vertical slope.

For the rock-mechanics analysis of the Siq, a 3D computer model of the rock walls on both sides of the Siq was created (Ruther 2015). Ideally this model should have covered the full height of both surfaces over the $1.2 \mathrm{~km}$ length of the Siq which would have resulted in a model of $2.4 \mathrm{~km}$ length with heights varying from about 70 to $120 \mathrm{~m}$ (Fig. 4).

Two methods were available for the development of the 3D surface model, laser scanning and photogrammetry. In lengthy investigations and discussions, the accuracy potential, the practicality and the cost of the two techniques were explored including considerations regarding the use of Unmanned Aerial Vehicles (UAVs), scaffolds and poles. It became obvious that neither method was capable in a practical sense of providing surface data beyond the areas which were visible from the ground, unless unrealistically high expenses were accepted. The final decision favoured laser scanning as the most feasible method and an extensive laser scan survey, limited to the rock surfaces visible from ground level, was subsequently completed by the Zamani research team, from the University of Cape Town. A number of individual boulders and sections of rock walls were modelled by PNP surveyors using Structure-from-Motion-Photogrammetry.

For the Siq survey, the scanner was positioned on the Siq floor at intervals of not more than 10 meters (Ruther et al. 2014). The lower wall areas over the entire length of the Siq were thus captured up to a height varying from 20 to $80 \mathrm{~m}$, depending on visibility (Fig. 5a). In addition to this, a 


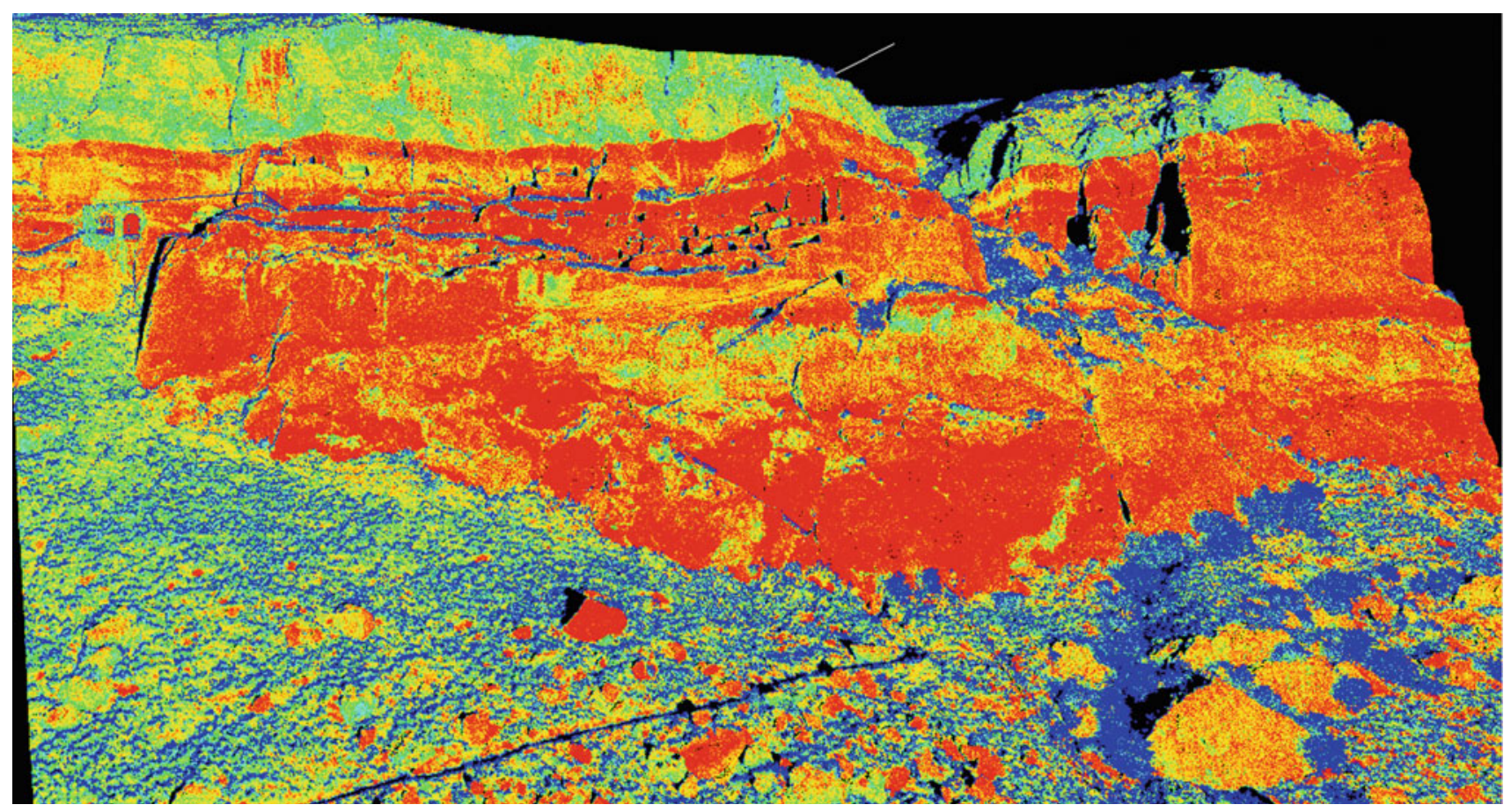

Fig. 3 Textured 3D model and reflectivity map of the cave monastery of Vardzia (Georgia) from TLS techniques

number of scans could be taken from points at the upper edge of the Siq (Fig. 5b). The scans at high elevations provided, in some cases, surface data from Siq floor to the top of the rock walls. The total number of scans in the Siq was 220 with an average point interval of approximately $3 \mathrm{~cm}$, resulting in a point cloud of five billion points. This is only a part of the complete point cloud which the Zamani team acquired for the Siq, Wadi Musa and Wadi Farasa. This collective point cloud comprised 25 billion points. The relative accuracy of points, i.e. the accuracy of neighbouring points is estimated to be in the order of a $\mathrm{cm}$ or better, whereas the absolute accuracy, i.e. the accuracy of points over the entire length of the Siq is in the one or two decimeter range. The final model (example in Fig. 6) can be viewed in $3 \mathrm{D}$ viewing and processing software. Coordinate and dimension measurements can be taken in applications such as the open source system Meshlab (meshlab.sourceforge.net). The 3D model and the GIS are referenced to UTM coordinates on WGS 84 (ITRF8) determined via GNSS survey by the Zamani team.

\section{Cross-Sections}

The 3D model of the Siq walls also had to be available in 2D formats for processing and display in a variety of CAD and analysis software applications (Ruther 2015). For this purpose sections and ortho-images were generated.
One hundred-and-twenty-one cross-sections at approximately right angle to the central axis of the Siq were generated from the 3D model at intervals of $10 \mathrm{~m}$ (Fig. 7).

\section{Ortho Images}

Sixty nine ortho-images (Fig. 8) of the Siq wall were created covering the full extent of the Siq rock walls (Ruther 2015). It is noteworthy that, due to the non-planar nature of the rock surface, it is not possible to create ortho-images which can be used for accurate measurements, as would normally be possible for ortho-images (Fig. 9). Thus these images are primarily useful for inspection of wall sections and annotations, whereas measurements must be done on the 3D model in 3D viewing and measurement software (such as Meshlab or Cloud Compare). Measurements on the ortho image are only correct for surfaces which are parallel to the projection plane of the ortho image. Deviations of the rock surface from this condition result in errors.

\section{Panoramas}

One hundred and two full dome photographic panoramas were acquired for the Siq of Petra, at an average interval between panorama stations of about $10 \mathrm{~m}$ (Ruther 2015). Each panorama was generated from 21 to 49 images 


\section{SIQ Sector - Elevations overview (with Satellite image)}

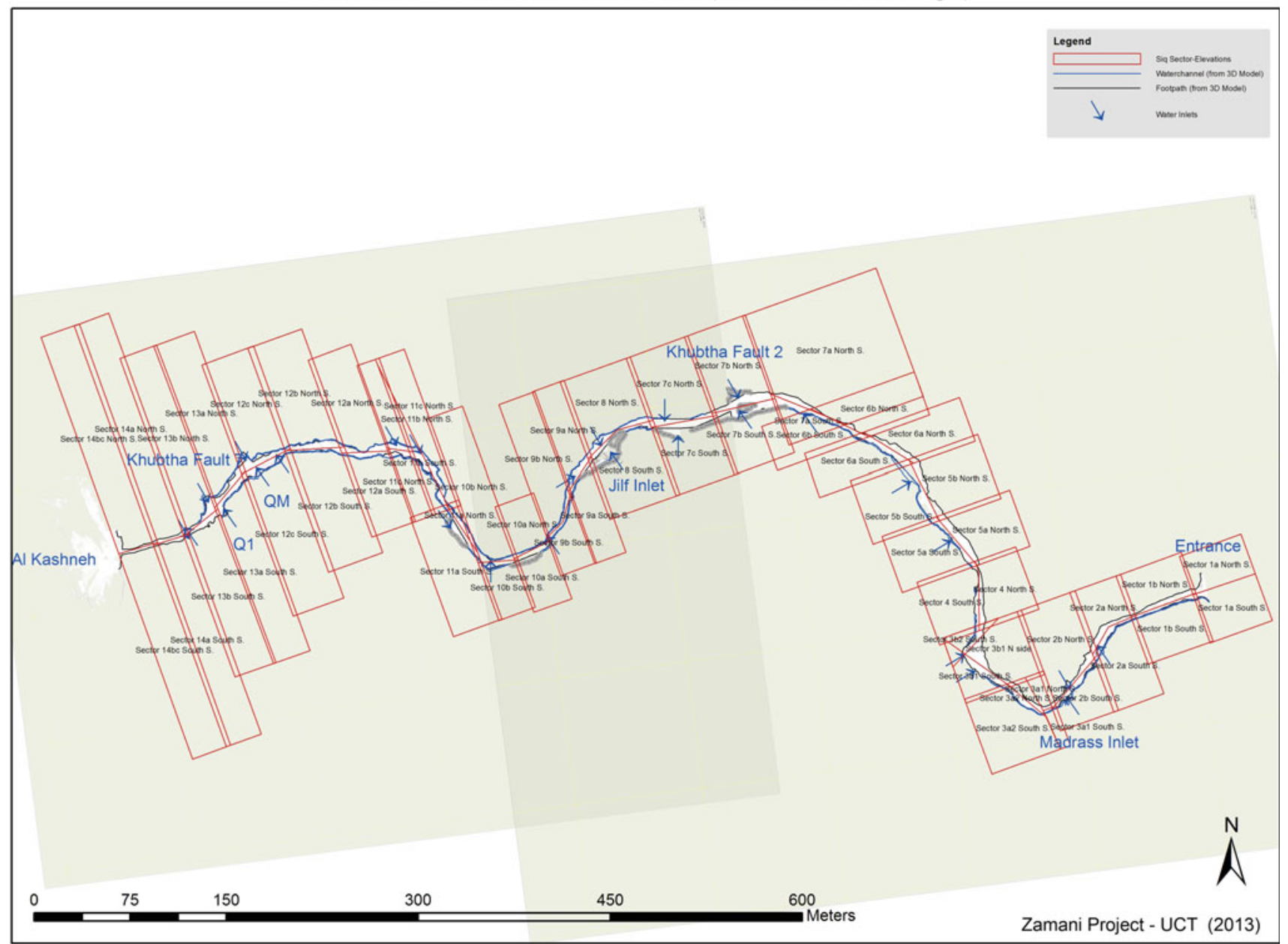

Fig. 4 Top view of $1.2 \mathrm{~km} \mathrm{Siq} \mathrm{point} \mathrm{cloud} \mathrm{(Courtesy} \mathrm{of} \mathrm{Zamani} \mathrm{Project)}$

captured with a Nikon D 200 camera equipped with a $10.5 \mathrm{~mm}$ lens. In each case the camera was pointed into six horizontal and one zenith direction. Images were then taken with a view to High Dynamic Range (HDR) processing and depending on the light conditions 3,5 or 7 bracketed images were acquired in each of the seven directions.

The panoramas were combined into a panorama tour which makes it possible to view the entire length of the Siq from the position of a person walking from the Siq entrance to $\mathrm{Al} \mathrm{Khazneh}$.

Such materials provided a very useful description and verification tool in the elaboration of the project, especially when not on site.

\section{Mineralogy and Petrography}

Weathering of rock can have a wide range of causes, all of which must be considered in an integrated approach before embarking on conservation activities. An example for such an investigation is the conservation of the rock hewn churches of Lalibela in Ethiopia.

The rock-hewn churches of Lalibela, included since 1978 in the UNESCO's World Heritage List, attracted the attention of the conservation science community because of their severe chemical weathering and physical decay (Fig. 10). Thin section study, X-ray diffraction (XRD) and SEM-EDS mineral composition of samples from seven rock-hewn churches (Biet Medhane-Alem, Biet Mariam, Trinity Church, Biet Giyorgis, Biet Emanuel, Biet Abba-Lebanos and Biet Gabriel/Rufael) were carried out. These investigations showed that the churches were carved in hydrothermally-altered and nearly aphyric vesicular basalts with incipient lateritization (Ruther et al. 2014). This is in contrast to the earlier literature on Lalibela which often reports the rock-hewn churches as being carved into "weathered basic tuffs". In reality, the geological materials are hydrothermally altered scoriaceous unit/s of massive to 
(a)

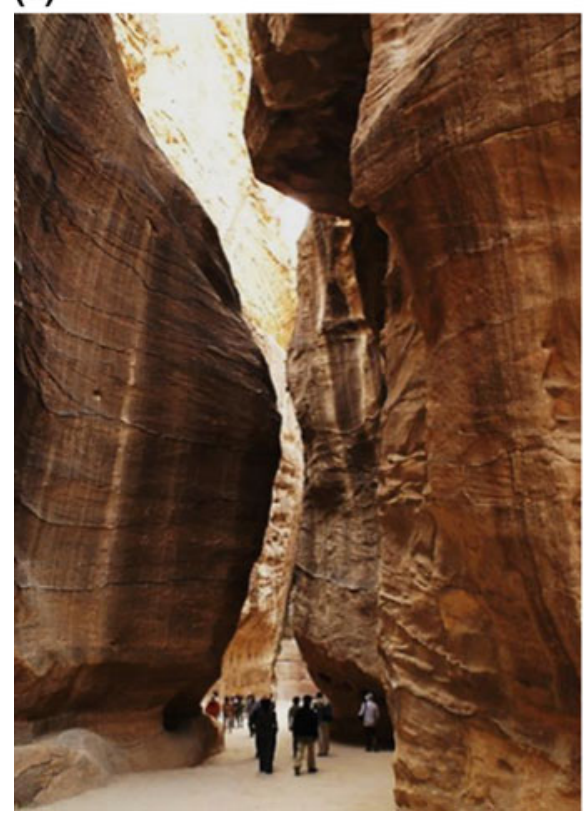

(b)

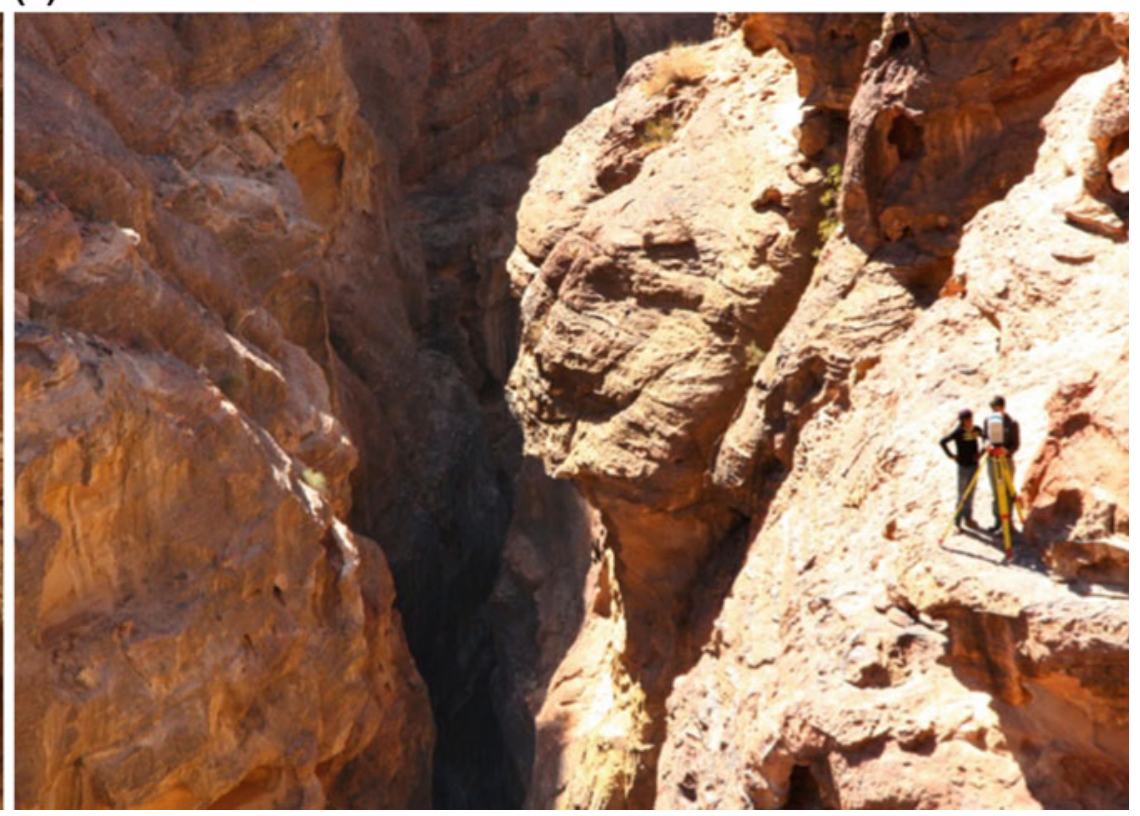

Fig. 5 Narrow passage in the Siq which makes the acquisition of upper parts of the slopes by TLS impractical if not impossible (a) and scanner positioned at one of the few places where scanning from the top was possible (b)

Fig. 6 Example of the Siq surface model. The large black area to the left is seen, in this perspective, from inside the rock wall whereas the smaller black patches inside the Siq are areas invisible to the scanner

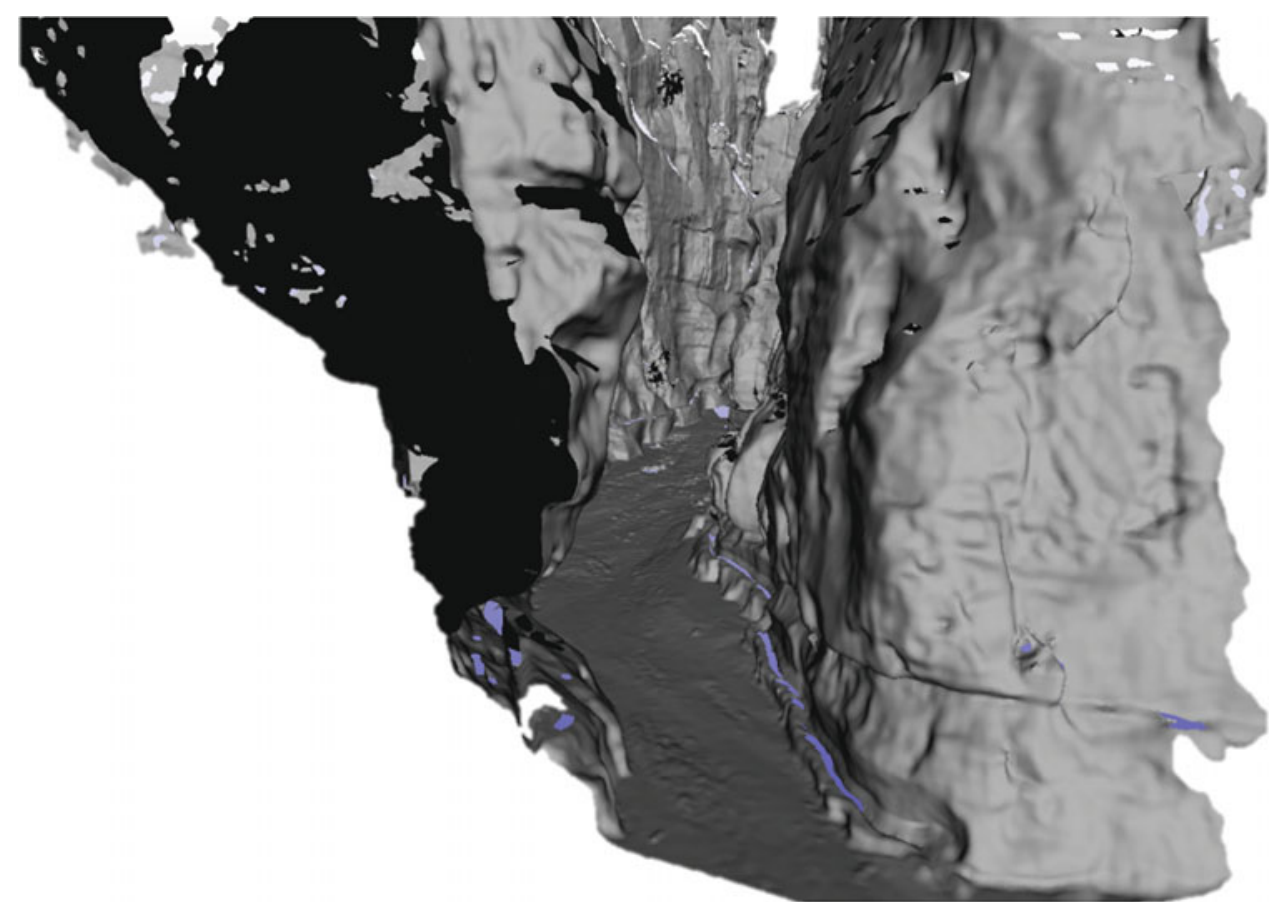

insights to unravel causes of deterioration of these World Heritage monuments.

Considering the heavy deterioration affecting the investigated rocks, the correct petrographic (basalt) and lithological (partly lateritized vesicular lava) definitions, coupled with the comprehensive hydrothermal mineralogy are of paramount importance to better understand the causes of slightly fractured basaltic lava still present as bedrock, and not a pyroclastic level sensu stricto. In fact, late-stage and post-magmatic phases (smectites, zeolites and calcite) scattered in the groundmass and filling the large subspherical vesicles represent a typical hydrothermal facies of continental flood basalts. Appropriate modal mineralogy and petrography of the Lalibela churches provided useful 
Fig. 7 Cross-section through the Siq. Invisible areas are indicated in red

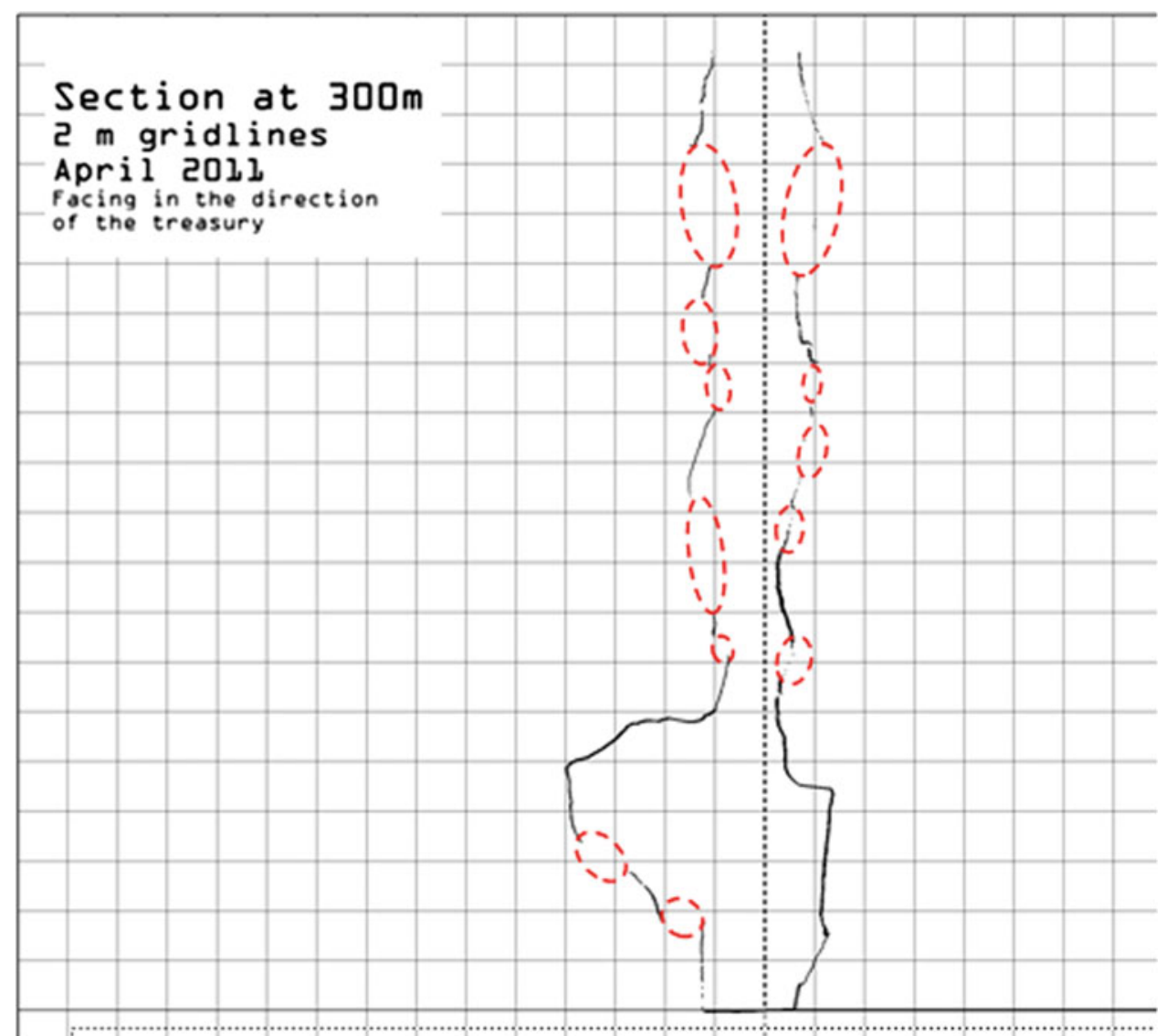

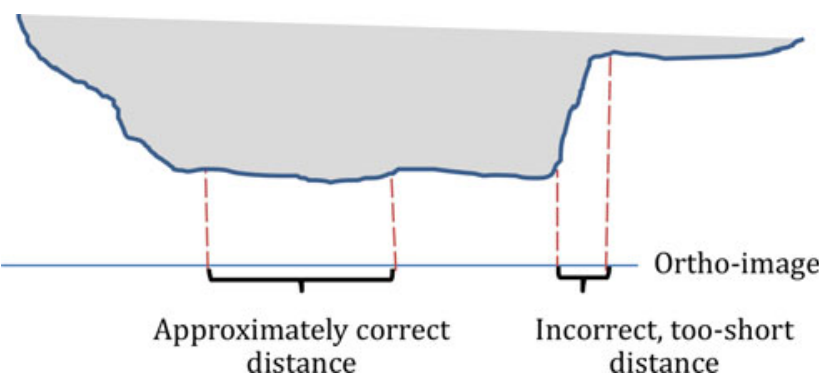

Fig. 8 Distortions in ortho image due to irregular surface shapes

their chemical weathering and physical decay and to plan conservation actions. The presence of swelling clay minerals (due to hydrolytic weathering of silicates), minor dissolution-crystallization processes of soluble salts and the whole inexorable lateritization processes, typical of regions with dry and rainy seasons, all concur in the deterioration of the rocks. Additionally, a recent study (Renzulli et al. 2011) emphasises how the high microporosity of the abundant zeolites, coupled with the wide range of apparent density and porosity to water saturation should now be considered and further investigated in the framework of future conservation studies of the Lalibela rock-hewn churches.
In conclusion, very often weathering processes depend on a variety of factors, to be jointly investigated in a comprehensive manner. Such weathering, even if dependent on micro processes may play a large role in the entire site conservation, as in the case of Lalibela reported in this paper.

\section{Rock Mechanic Parameters}

Rock mechanic parameters are of paramount relevance for the conservation of rupestrian sites. Generally, since such sites are primarily carved into soft rocks, the strength and deformability parameters of rock material refer mainly to the rock mass, which is composed of the intact rock and the joint family, depending on the scale of analysis. The intact rock is well described and characterized by UCS values whereas the rock mass is described and characterized by indices (e.g. RMR, Q_system, GSI) as a result of UCS, joints and water condition combination. The following example is taken from the investigations for the consolidation of the remains of the destroyed Buddha Statues in Bamiyan (Afghanistan).

The rock mass of Bamiyan (Afghanistan) is composed of continental lithotypes, likely coming from the dismounting of surrounding morphological peaks and deposition in a 


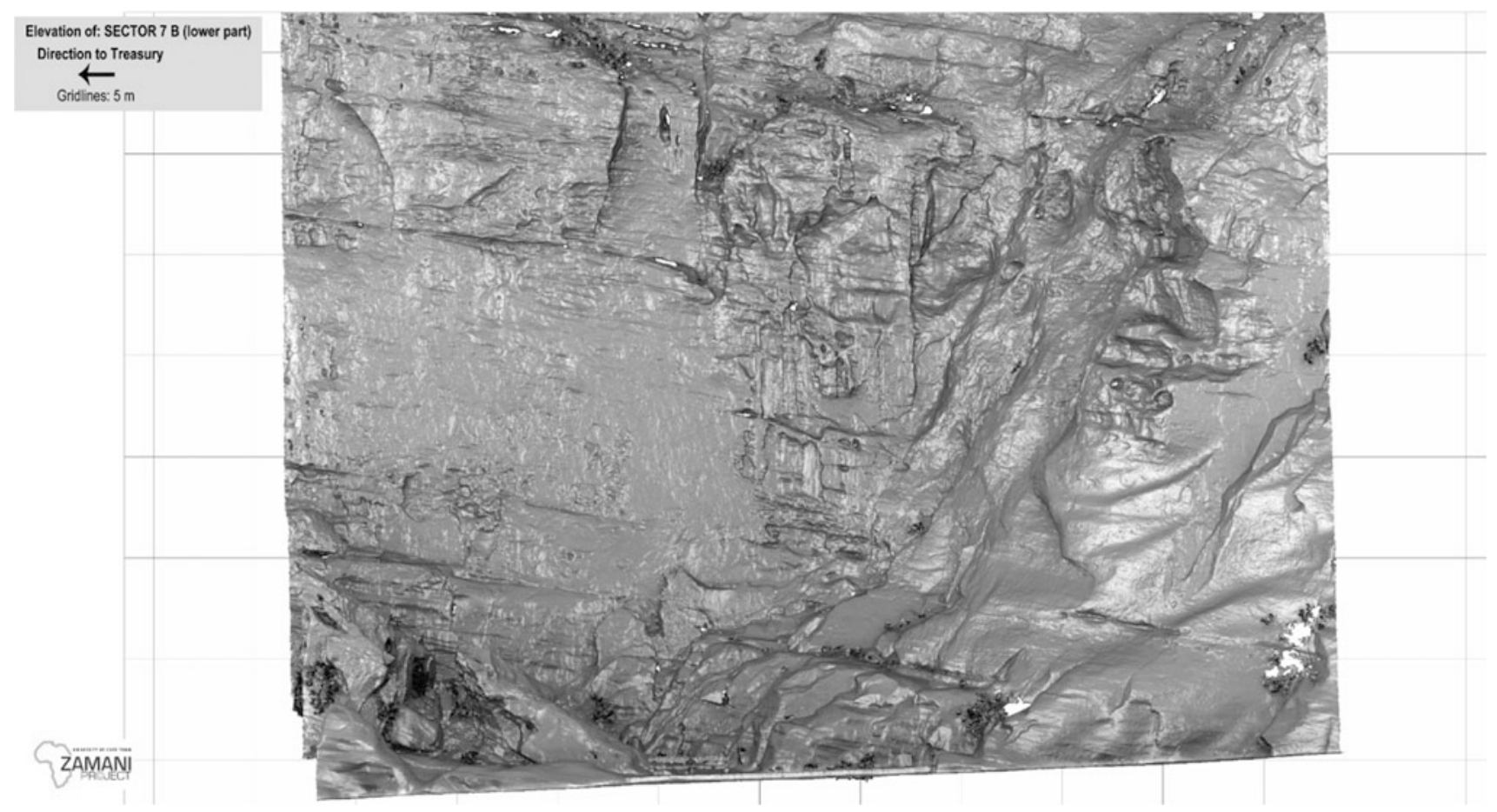

Fig. 9 Ortho image of rock wall showing surface details

flood plain and small lagoon. The subsequent river erosion produced the present morphology for the part where the rupestrian settlement is located (Delmonaco and Margottini 2014)

The cliff and niches are composed of alternating conglomerate and siltstone (yellow at the bottom and red in the middle of the cliff); the conglomerate, with different sized pebbles (coarse, mid and fine-grained), is the predominant material in the cliff and exhibits a moderate cohesion. The siltstone is interlayered with the conglomerate strata. The mean value for the uniaxial compressive strength of the conglomerate is $2.99 \mathrm{MPa}$, whereas the value for the uniaxial compressive strength of the siltstone is $6.91 \mathrm{MPa}$ (Feker 2006). Point load data10 show that the average UCS values are 11.0 MPa for siltstone and 5.6 MPa for conglomerate.

Accordingly, the siltstone is apparently stronger than siltstone. A simple test with immersion in water, clearly shows a potential and relevant slaking attitude of the material, clearly not visible on site because of the low rainfall rate in the area (annual average rainfall equal to $162.56 \mathrm{~mm}$ ) (Margottini 2014a, b).

The mechanism for the swelling is likely dependent on the presence of a cement carbonate in the conglomerate and the absence of such permanent cement into the sandstone, as revealed by microscopic thin section and $\mathrm{x}$-ray diffraction (Fig. 11b, c).

As a general conclusion we note that relevant geomechanical parameters also depend on the local environment and a global and detailed investigation must be performed to avoid unexpected problems. In this case, considering the importance of water with respect to the adherence of potential anchors, as well as the use of water or air as drilling head cooling fluid, the complete understanding of rock behavior in different conditions is essential.

\section{Semi-automatic Discontinuity Detection and Analysis}

In order to implement a kinematic analysis and further hazard analysis in rock slopes, discontinuities must be identified and mapped. Availability of TLS data make this step more advanced, allowing the structural analysis to be implemented through a semi-automatic method. As an example, the case study of the rock-cut city of Vardzia is reported. Vardzia is a cave monastery located in south-western Georgia, excavated from the slopes of the Erusheti mountains on the left bank of the Mtkvari River. The main period of construction was the second half of the twelfth century. The caves stretch along the cliff for some eight hundred meters and range in height over fifty meters within the rocky wall. The monastery consists of more than six hundred hidden rooms spread over thirteen floors, which protected the monastery from the Mongol domination (Fig. 12).

Discontinuities data were obtained, in Vardzia (Georgia) both during field survey and through the elaboration of TLS 
Fig. 10 a Location of the Lalibela site; $\mathbf{b}$ distribution of the 11 rock-hewn churches: 1 : Biet Medhane-Alem (BA); 2: Biet Maryam (BM); 3: Biet Masqal; 4: Biet Danagel; 5 and 6: Trinity Church (BT, i.e., Biet Debre-Sina and Biet Mikael-Golgota); 7: Biet Amanuel (BE); 8: Biet

Maqorewos; 9: Biet

Abba-Libanos (BL); 10: Biet GabrielRufael (BR); 11: Biet Giyorgis (BG); c view of Biet Giyorgis church; d view of Biet Abba-Lebanos church (Renzulli et al. 2011)

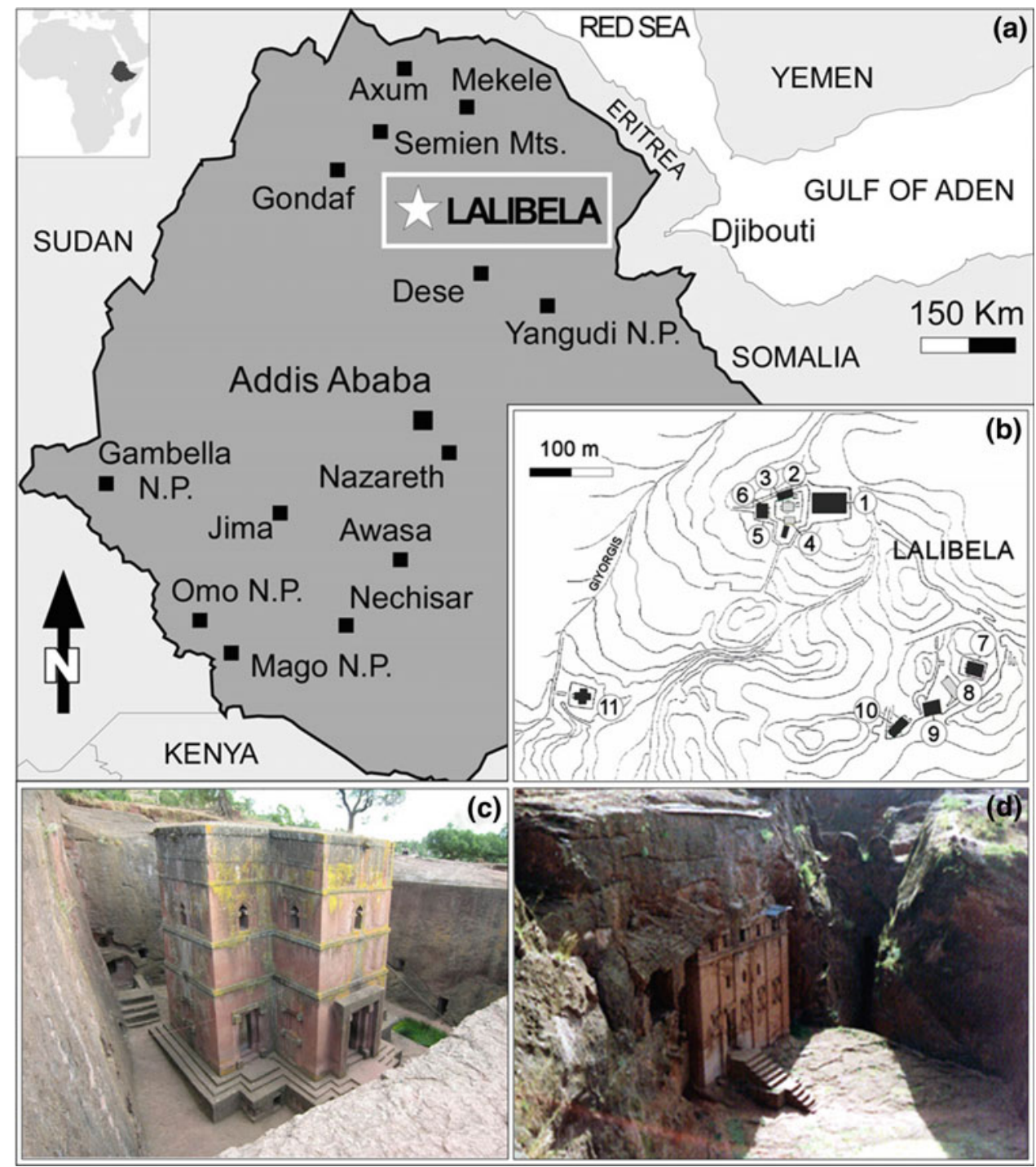

with a specific software, Coltopo3D®, suitable to detect slope and slope direction of the many outcropping surfaces11. Coltop3D software performs structural analysis by using digital elevation model (DEM) and 3D point clouds acquired through terrestrial laser scanners. A colour representation merging slope aspect and slope angle is used in order to obtain a unique code of color for each orientation of a local slope (Fig. 13). Thus a continuous planar structure appears in a unique colour (Metzger et al. 2009).

\section{Kinematic Analysis}

Most classifications of mass movements and hazard assessment in rock slopes use relatively simple, idealized geometries for the basal sliding surface (BSS), like planar sliding, wedge sliding, toppling or columnar failures. For small volumes, the real BSS can often be well described by such simple geometries (Oppikofer et al. 2011). Extended and complex rock surfaces, however, can exhibit a large number of mass movements, also showing various kinds of kinematics. As a consequence, the real situation in large rock surfaces with a complicated geometry is generally very complex and a site dependent analysis, such as fieldwork and compass, cannot comprehensively reveal the real situation.

The availability of digital slope surface data can offer a unique chance to determine potential kinematics in a wide area for all the investigated geomorphological processes. In more detail, the proposed method is based on least-squares-fitting of planes to point clusters extracted by moving a sampling cube over the point cloud. If the associated standard deviation is below a defined threshold, the cluster is considered acceptable. By applying geometric criteria it is possible to join all clusters lying on the same surface; in this way discontinuity planes can be 
(a)

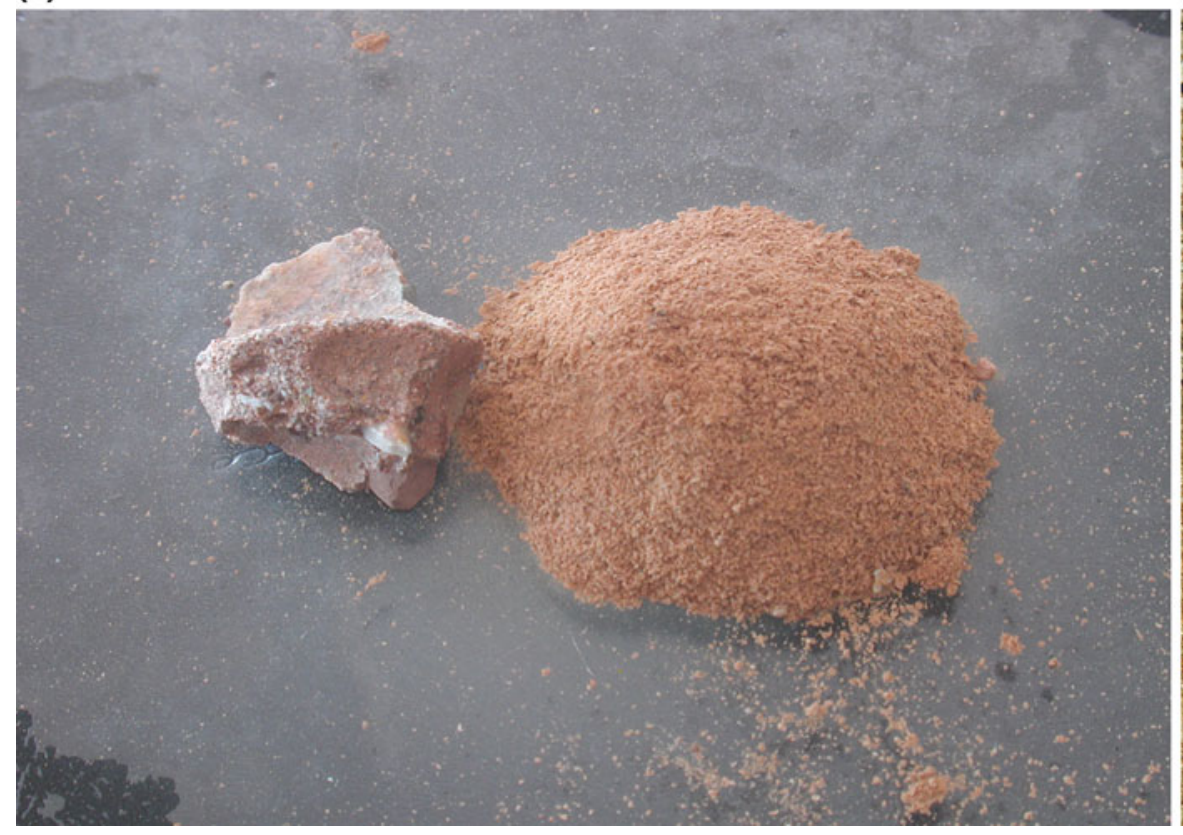

(b)

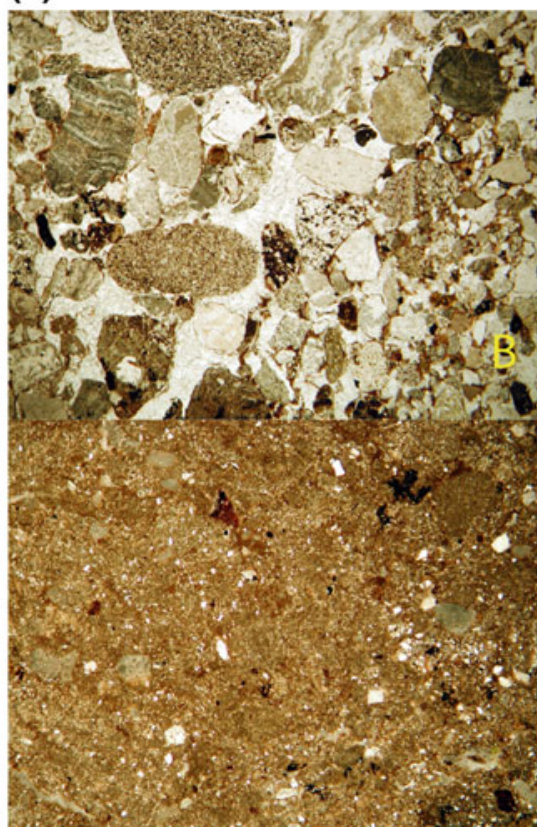

Fig. 11 Stability of conglomerate (left in a) and degradation of siltstone (on the right in a) when saturated. Thin section of conglomerate with white carbonate cement (b) and thin section of siltstone (c) (Margottini 2014a, b)

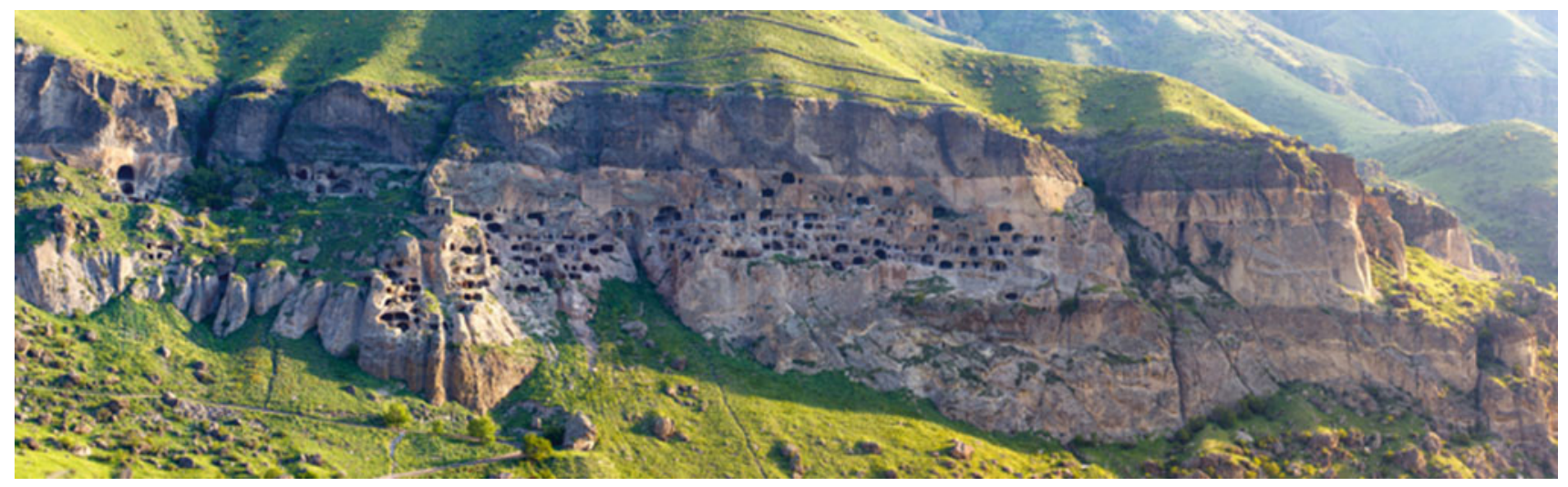

Fig. 12 General view of rock-cut city of Vardzia (Georgia)

reconstructed, rock mass geometrical properties can be calculated and, finally, potential kinematics established.

As previously mentioned, the Siq of Petra (Jordan), is a $1.2 \mathrm{~km}$ naturally formed gorge, with an irregular horizontal shape and a complex vertical slope that represents the main entrance to Nabatean archaeological site. In the Siq, discontinuities of various type (bedding, joints, faults), mainly related to geomorphological evolution of the slope, lateral stress released, stratigraphic setting and tectonic activity can be recognized. Rock-falls have been occurring, even recently, with unstable rock mass volumes ranging from $0.1 \mathrm{~m}^{3}$ up to over some hundreds $\mathrm{m}^{3}$. Slope instability, acceleration of crack deformation and consequent increasing of rock-fall hazard conditions, could threaten the safety of tourists as well as the integrity of the heritage site.

Thus, for the identification of the main rockfall source areas, a spatial kinematic analysis for the whole Siq was performed, by using discontinuity orientation data extracted from the point cloud by means of the software Diana (Casagli and Gigli 2011). Orientation, number of sets, spacing/frequency, persistence, block size and scale dependent roughness were obtained combining fieldwork and automatic analysis. This kind of analysis is able to establish where a particular instability mechanism is kinematically feasible, given the geometry of the slope, the orientation of discontinuities and shear strength of the rock. 


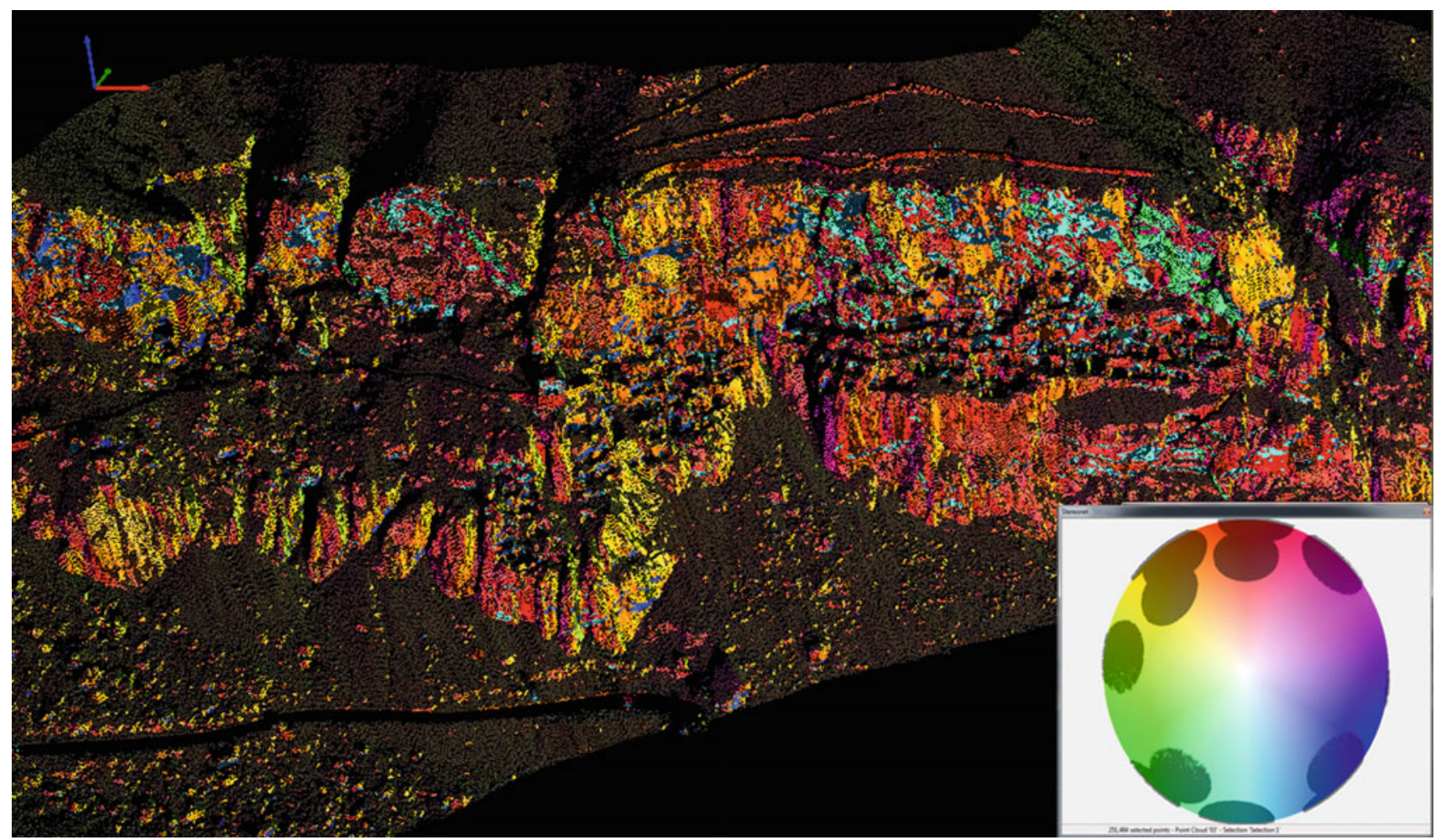

Fig. 13 The exposed rock faces of Vardzia cliff and detected slope aspect and slope angle, also on a Schmidt-Lambert stereonet (Margottini et al. 2016a, b, c, d)

The final outcome of this project was a detailed landslide kinematic index map, reporting main potential instability mechanisms for a given area. The kinematic index was finally calibrated for each instability mechanism (plane failure; wedge failure; block toppling; flexural toppling) surveyed in the site.

A synthetic view was also provided, integrating all the different probability of occurrence for the different kinematic conditions, into a single evaluation. This elaboration, as in Fig. 14, may help in the general management of the site, identifying the most endangered places, however a detailed case by case investigation is still required.

\section{Infrared Thermographic Analysis (IRT)}

InfRared (IRT) Termography is a non invasive technique that has also recently been applied to the rapid detection of slope portions, mainly investigating thermal anomalies in the rock mass and along the discontinuities.

Thermal imaging is based on the detection of electromagnetic waves in the thermal infrared spectrum, which are converted to electrical signals. All objects with temperature above $0 \mathrm{~K}\left(-273.15^{\circ} \mathrm{C}\right)$ emit characteristic IR radiation, which can then be displayed in the visible spectrum by thermal imaging cameras.
The IRT detection method relies on air circulation and ventilation through open joints and cracks when, in winter, the warmer subsurface communicates with the (colder) ground surface; cracks can thereby be identified as relatively warm areas using IRT. The contrast between temperatures deep in the rock, which at depths of several meters generally correspond to the local mean annual temperature, and the actual temperature at the ground surface is accentuated by airflow in the open joints, cracks, and cavities. In winter, air circulating through open joints absorbs heat from deep within the rock mass, becomes warmer and lighter than the ambient air, rises, and is expelled through joints and caverns at the ground surface (Baron et al. 2014).

Within the obtained surficial temperature maps (thermograms) shown in Fig. 15, the temperature is represented by means of a colour scale, in which the higher temperatures are displayed by the lighter colours, whereas the colder temperatures by the darker ones. In order to obtain a comparison with TLS data, IRT data can be referenced to the laser scan data (Gigli et al. 2013).

The higher the temperature of an object of interest, the greater will be the intensity of emitted radiation. This means that larger temperature differences in an assessed area present brighter contrast levels in the image.

Water leaks and moisture zones are also potentially visible and detectable by using IR images, due to the lowering 


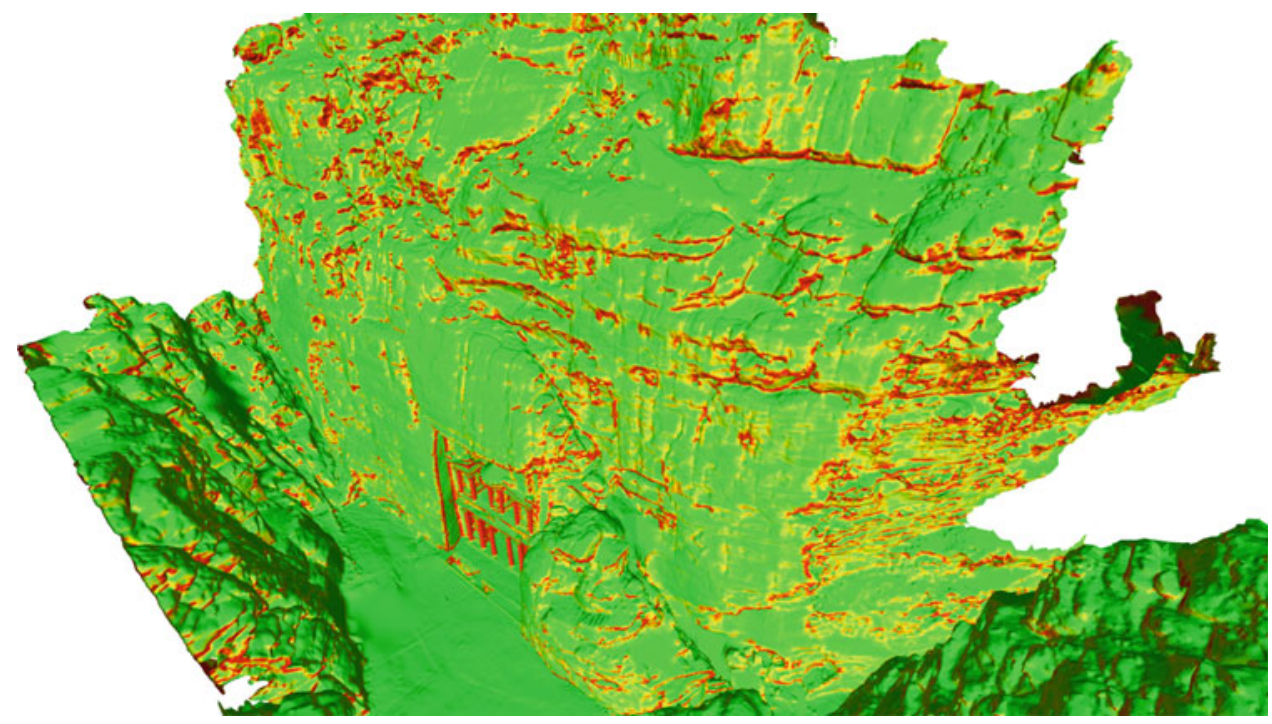

Fig. 14 Integrated result from the 3D individual kinematic analysis for the different analyzed instability mechanisms (block toppling, flexural toppling, wedge failure, plane failure and free fall) in the
Treasury area (Petra, Jordan). The probability of occurrence (hazard) is expressed following a common colour scale ( $0-30 \%$ of probability to be involved in a kinematic process)

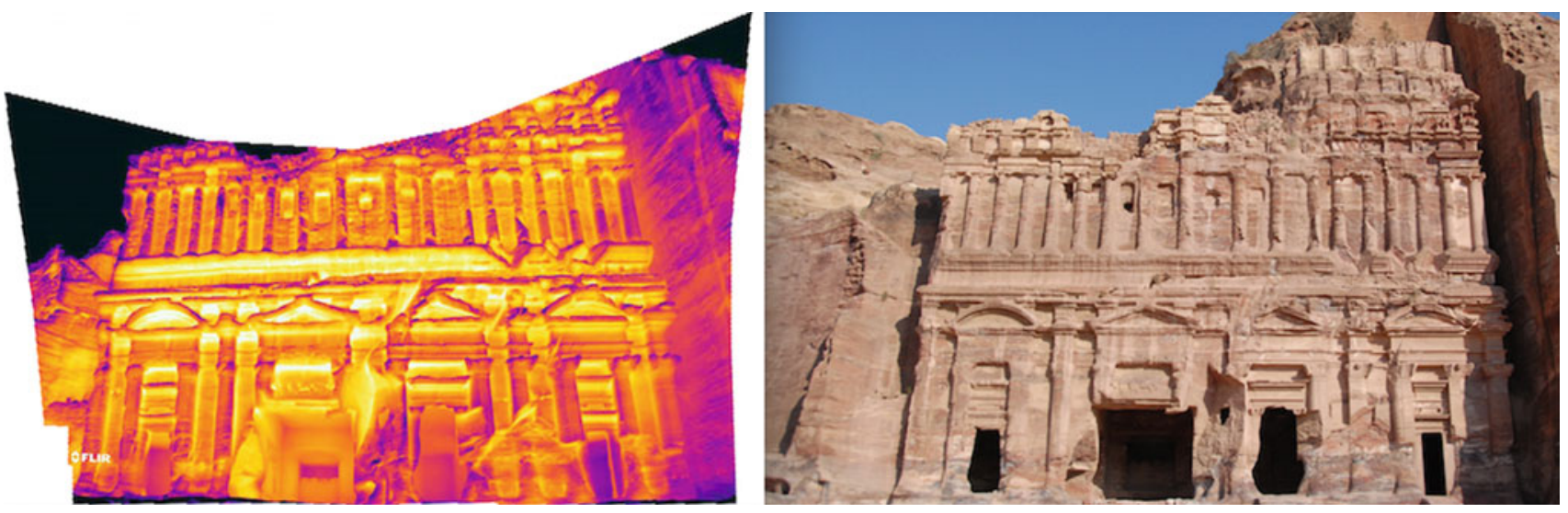

Fig. 15 Thermal image of the Palace Tomb in Petra, compared with the image as seen by a normal camera

effect of evaporation which cools moist areas (Clark et al. 2003).

\section{Thermal Influence}

The changing climatic conditions apparently accelerate the deterioration processes of rocks as the host environment of several rupestrian sites or as the building material, especially when the historic monuments are in sight of the study. As can be confirmed by many researchers moderate and cyclic nature of temperature changes may facilitate thermally driven processes even in mid-latitudes (Gomez-Heras et al. 2008a).

The heat flow penetrating into the rock mass produces a temperature field which changes with heating and cooling phases as a function of depth. Temperature oscillations produce cyclic thermal strains in rock masses which result in deterioration processes associated with crumbling, cracking and jointing, opening/closing of joints/fractures, and in jointed rock masses may initiate thermally driven displacements ranging from slow creep (block ratcheting in terms of Pasten et al. (2015), further toppling, and tilting to rapid movement in the form of rock cliffs overturning to rock falls. There are several slope failures, where no significant trigger was proposed and the rock failure mechanism remained unclear were recently recognized as hazards triggered by meteorological factors, including temperature variations (Dehn et al. 2000; Vargas et al. 2004; Krähenbühl et al. 2004; Gunzburger et al. 2011; Hales and Roering 2007; Vlcko et al. 2009; Bakun-Mazor et al. 2011, 2013; Gischig et al. 2011a, b; Grøneng et al. 2011; Hatzor 2004). 
As an example we may present our experience with Spis Castle (UNESCO site) from eastern Slovakia where since 1980 and 1992 three TM-71 type crack-gauges (TM-71) installed at the castle subgrade operate. Within this period mean annual displacement recorded at this site reached the value of $0.3-0.9 \mathrm{~mm}$ (mean value $0.33 \mathrm{~mm} / \mathrm{yr}$ ). According to the rate of displacements the slope movements maybe assigned as extremely slow (Varnes 1978). Significant for the monitoring records is that regardless of rainfall data as the most frequent slope movements trigger, the increment in the rate of displacement is quasi "stable" and as can be seen corresponds to the cyclic temperature variations (Fig. 16).

In order to get better support of this idea, thermomechanical behavior of the travertines were tested. Cylindrical samples of $34 \mathrm{~mm}$ diameter and $50 \mathrm{~mm}$ height, cut in three axis were prepared, surface faces of specimens remained unpolished in order to avoid sealing of their pores and cavities. The samples were subject to three temperature variations simulating real seasonal insolation cycles within the range of -20 to $50{ }^{\circ} \mathrm{C}$ (measured directly in the centre the rock sample) using a thermodilatometer VLAP (Vlčko et al. 2007), Fig. 17. Thermal expansion was measured with quartz rods attached to linear variable differential transformers (LVDT) in six consecutive thermal cycles with temperature rate $0.3{ }^{\circ} \mathrm{C} / \mathrm{min}$. The number of thermal cycles corresponds to the amount of mean annual rock face temperature reaching the temperature difference of $35^{\circ} \mathrm{C}$.

The highest value of linear thermal residual strain or plastic deformations (in some papers assigned as residual dilation) was determined with the max value $\Delta \mathrm{Lr}=3.9 \times$ $10^{-6} \mathrm{~m}$, which means that $10 \%$ of recorded rate of displacements are triggered by the temperature fluctuations. If we calculate that in the natural conditions volumetric (three dimensional) deformation is the usual case, the percentage is even higher.

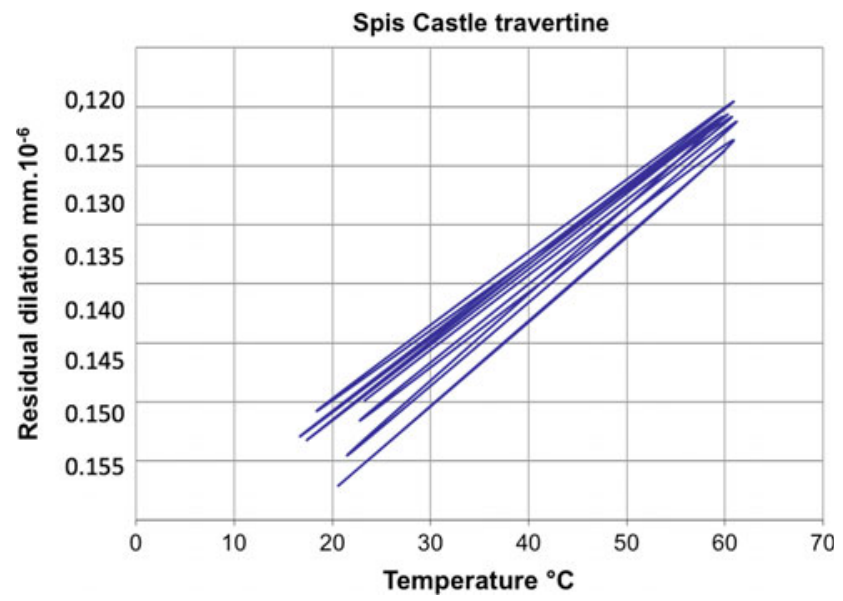

Fig. 17 Residual dilation vs temperature determined in thermodilatomer by multiple test performed within the temperature range 20 $60{ }^{\circ} \mathrm{C}$

Since the maximum rock face temperature reaches the difference in temperature of $35{ }^{\circ} \mathrm{C}$ several times per year one must conclude that the permanent dilation or plastic deformations significantly contribute (up to 20\%) to rate of movements, that despite the fact that lateral spreading is the representative mode of failure at the Spis Castle.

\section{Monitoring}

Landslide monitoring is required for a wide variety of reasons. These may include: the determination of the extent, magnitude and style of landslide movement, risk and even emergency risk management assessments and/or assistance with the design and implementation of site remedial and/or mitigation works.
Fig. 16 Temperature versus displacements

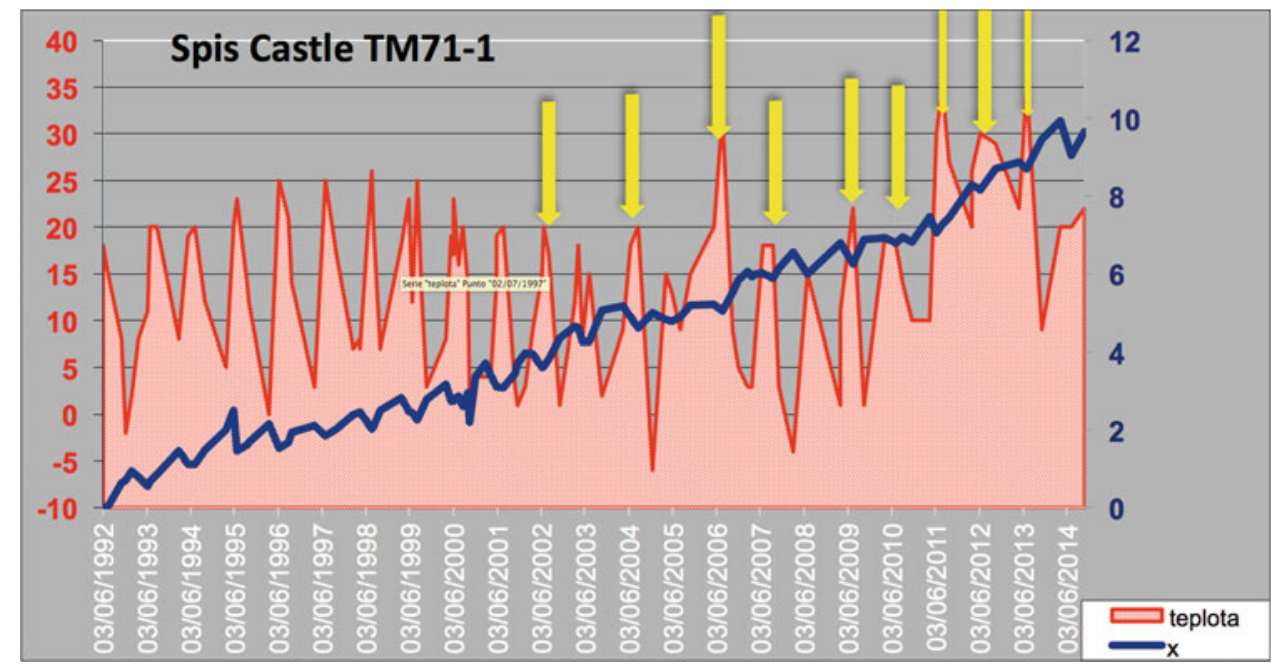


Since each monitoring project has specific requirements, the measuring device used for deformation monitoring depends on the application, the chosen method and the required regularity and accuracy. Therefore, monitoring of slopes or landslide areas can only be defined, designed and realized in an interdisciplinary approach (Wunderlich 2006). A close cooperation with experts from geology, geophysics and hydrology together with experts from any measurement discipline such as geodesy and remote sensing and other academic fields is an indispensable requirement.

Following are some examples of advanced monitoring systems for the control of important archaeological sites.

\section{Ground Based Radar Interferometry}

Large vertical rupestrian sites, in open space conditions, can be effectively monitored, with high resolution and accuracy, through a new ground based remote sensing investigation: radar interferometry. An application is presented in the case study of Vardzia (Margottini et al. 2015).

Considering the morphological settings of Vardzia, (slope extent ca. $105 \mathrm{~m}^{2}$ ) and slope instability processes (different typologies in size, magnitude and probability of occurrence), a new advanced simple and flexible monitoring system has been implemented in order to obtain measurements, processing and remote control in real time, and to transform in future, the monitoring system into a warning system. The system adopted for the monitoring of the entire cliff is based on ground based interferometric radar. This equipment allows the monitoring of ground surface displacement, along the line of sight, with a resolution of $\mathrm{mm}$.

The radar system is the Stepped-Frequency Continuous Wave (SF-CW) coherent radar with SAR and interferometric capabilities. The acquisition station has been realized with the valuable support of the NACHPG and the pre-acquisition and start up activities were finalised and calibrated during the last field mission. The above mentioned technique (SF-CW) allows the resolution of the scenario along range direction independently of the distance (range resolution up to $0.75 \mathrm{~m}$ ).

The SAR technique also allows the resolution of the scenario along cross-range direction independently (in the angular value) of the distance (cross-range resolution up to $4.3 \mathrm{mrad}$ ). The differential interferometry technique enables the measure of the displacement of the objects to be resolved through coupling SF-CW analysis. The system was installed in May 2012. As of this paper it has been continuously operating. The radar configuration adopted is reported in the following table, the "selection mask" contains about 50,000 points (Table 1).

The TLS derived DTM was used as 3D model for the visualization of the main monitored quantities (displacement and velocity) as collected and stored in real time by the monitoring system. The monitoring system is actually close to the end of the first 6 months of acquisition and the preliminary results are quite stable and promising.

With the exception of some ostensible changes in individual control points (mainly due to noise factors related to vegetation) the investigated area is stable and under control (Fig. 18). In the next 6 months on site verification of the main critical outcomes of the monitoring systems will be carried out along the cliff in order to calibrate and correct the results and define the most active zones in which downscaling of the landslide hazard and risk assessment is recommended.

Recent elaboration from Ilia University in Tbilisi, covering the time period 2013-2014, clearly identified 5 major areas of deformation (Fig. 16), one of which was stabilized in summer 2015 .

\section{Satellite Radar Interferometry}

Petra is a famous archaeological city carved out of stone, hidden by towering sandstone mountains in Jordan. Although uninhabited today, during ancient times Petra was a wealthy trading town, capital of the Nabataean kingdom. The archaeological site is composed by many historical monuments and the Siq, a $1.2 \mathrm{~km}$ naturally formed gorge in the Sandstone Mountains that served, during the Nabataean times, and still today, as the main entrance to Petra. Slopes are continuously affected by rock falls and local sliding events, involving volumes from less than $1 \mathrm{~m}^{3}$ to a few hundreds $\mathrm{m}^{3}$ (Alberti et al. in printing).

An area of about $50 \mathrm{~km}^{2}$, including Petra Archaeological Park and its neighbouring, was analysed with the SqueeSAR technique, an advanced InSAR algorithm. The analysis of 38 satellite radar images, acquired between 2003 and 2010, allowed the identification of about 62,000 measurement points for which it was possible to estimate the displacement time series along the satellite line of sight.

Potentially unstable rock blocks with medium-large size (> 50-100 m3) and already occurred rock falls, also involving heritage sites, were investigated, also through the comparison between satellite and ground based geotechnical 
Table 1 Main parameters of radar configuration in Vardzia (Georgia)

\begin{tabular}{|l|l|l|}
\hline Topic & Dimension & Value \\
\hline Distance from the slope & $(\mathrm{m})$ & $350-500$ \\
\hline Antenna beam width & $(\mathrm{deg})$ & $>70$ \\
\hline Number of points & - & 50,000 \\
\hline Range resolution & $(\mathrm{m})$ & 0.5 \\
\hline Cross range resolution & $(\mathrm{mrad})$ & 4.3 \\
\hline Scanning time & $(\mathrm{min})$ & 5 \\
\hline
\end{tabular}

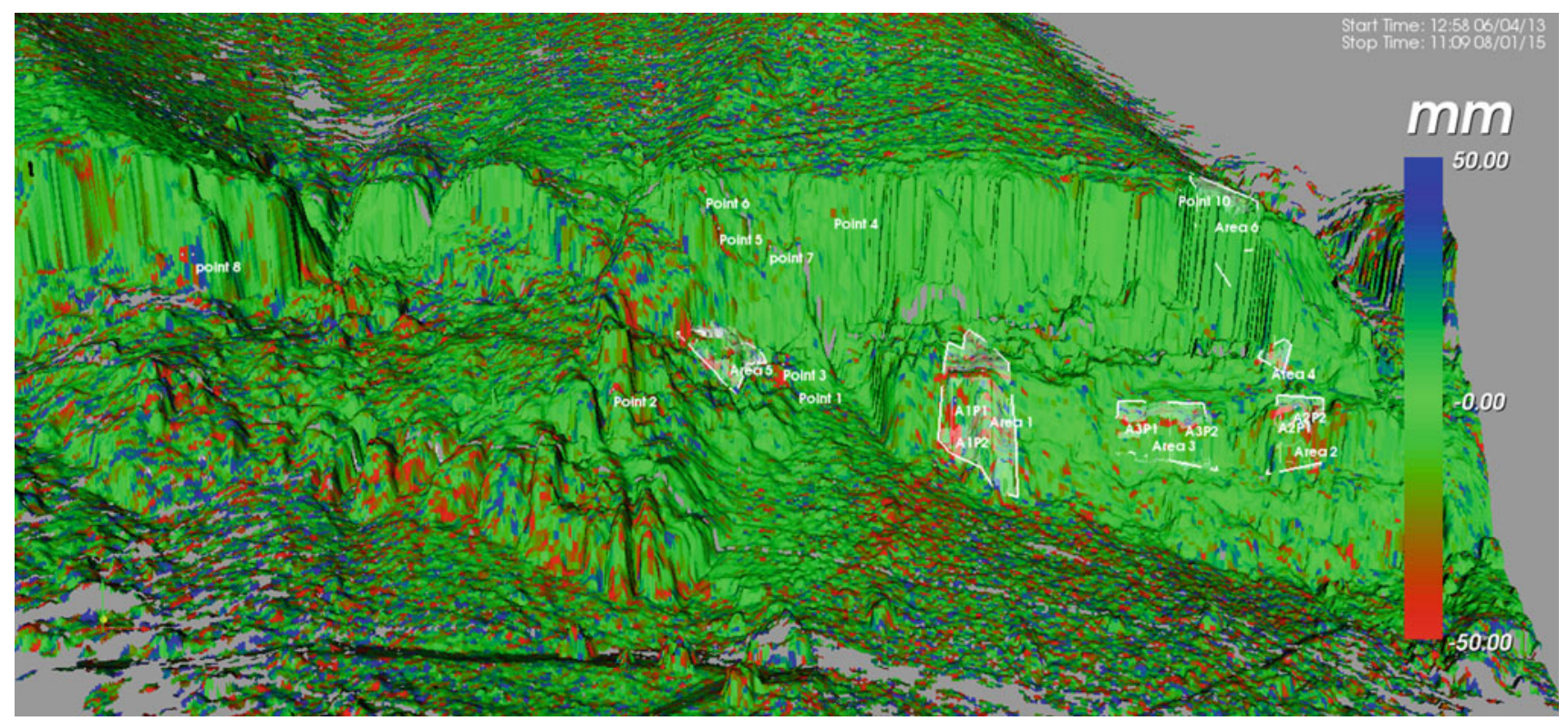

Fig. 18 Displacement detected from ground based radar interferometry on the rock cliff of Vardzia in the period 6 April $2013-8$ January 2015. Displacements are plotted against distance from the Radar installation
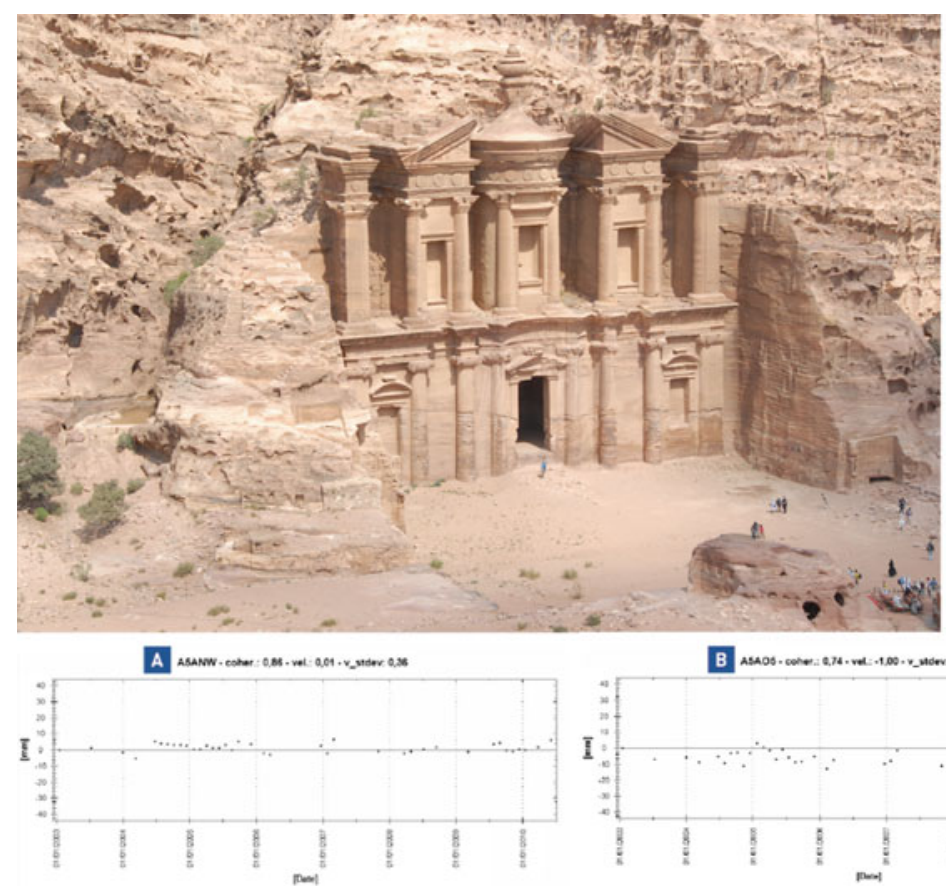
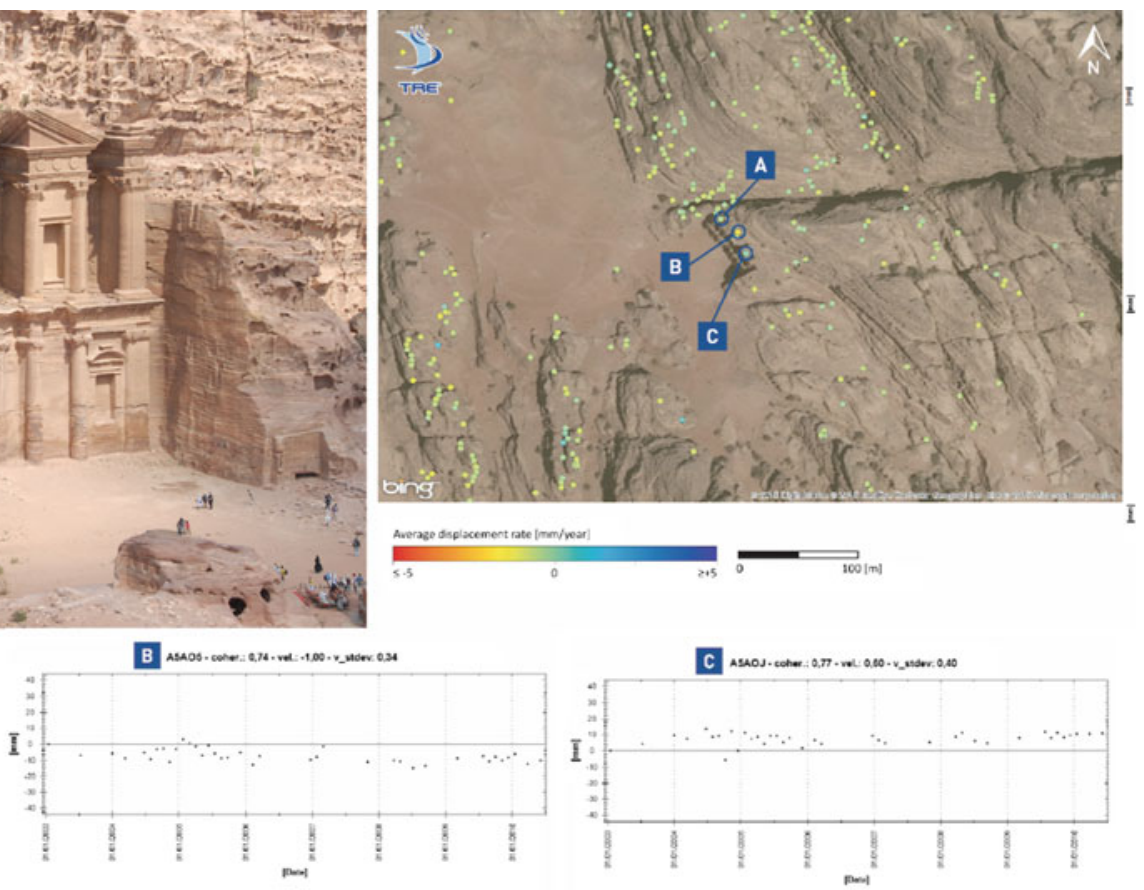

Fig. 19 Satellite radar interferometry investigating the long term stability of El Dir (Monastery) in Petra 


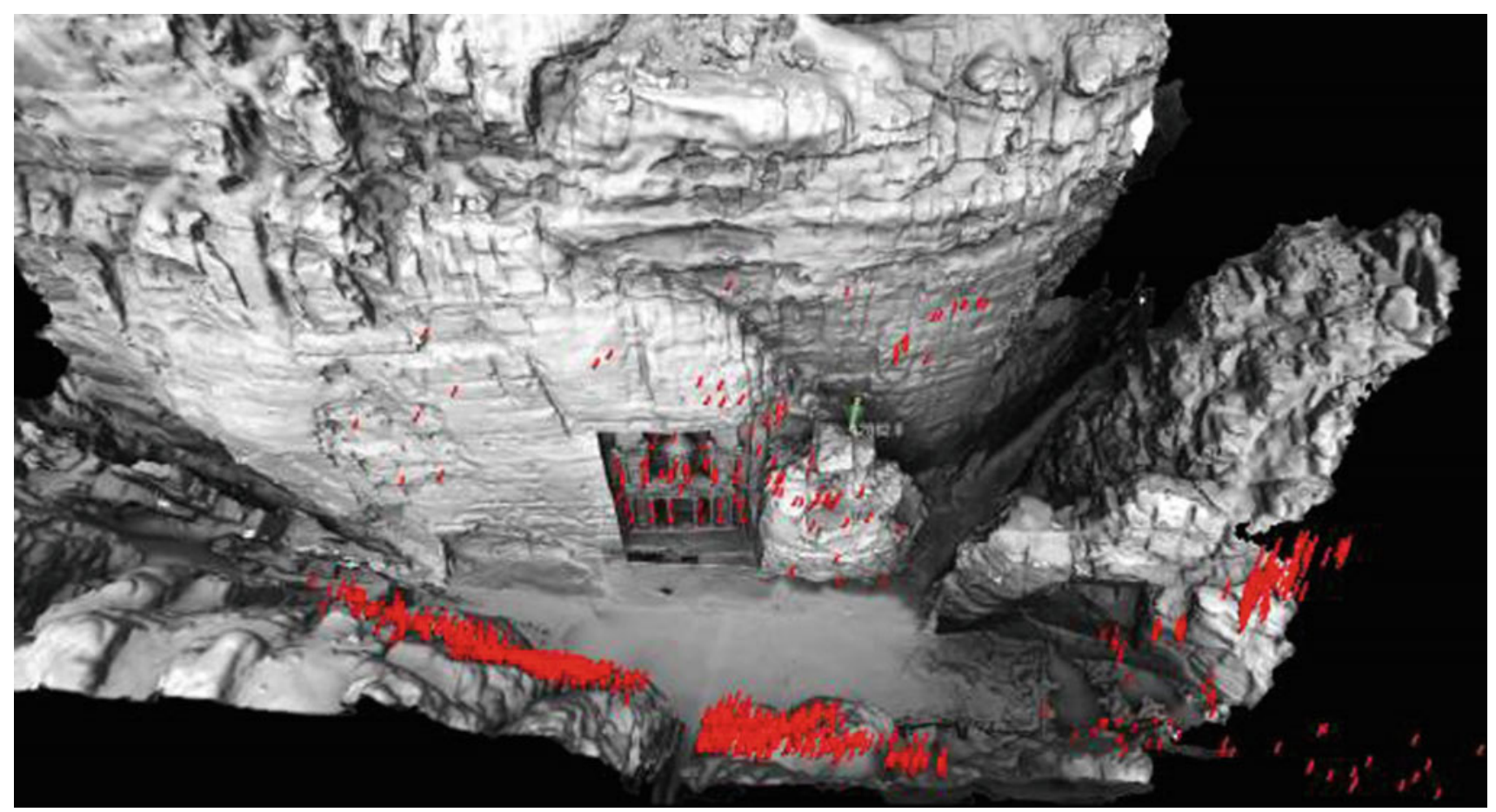

Fig. 20 Reflector-less surveyed points in the Treasury area (Petra, Jordan), superimposed on the terrestrial laser scanner

monitoring. Results of the analysis show that the area of Petra Archaeological Park is relatively safe from medium-large size rock fall (Fig. 19).

A possible seasonal effect on rock slope and monuments is evident, without a major permanent ground deformation, potentially leading to incipient collapse.. Minor rock falls $\left(<50 \mathrm{~m}^{3}\right)$ are clearly not detectable with medium-resolution satellite imagery, such as the one used in this study. In any case, further analyses may consider the use of the new satellite radar sensors (e.g. COSMO-SkyMed), characterized by a significant increase in both, spatial resolution of the data, and temporal sampling of the acquisitions, compared to those available until 2007.

\section{Reflector-Less Robotic Surveying}

For monitoring rock slope instability processes, geomatics methods are largely applied. Landslides are monitored by using Total Stations (Stiros et al. 2004; Tsai et al. 2012) and laser scanners, both conventional (Kasperski e al. 2010; Lichun et al. 2008) and recent models capable of fullwaveform analysis (Mallet and Bretar 2009; Pirotti et al. 2013).

All geomatics-related activities should be integrated with geomorphological and geotechnical surveys, in order to better understand the potential failure mode of the landslide and set up a model; this analysis is also useful for early warning.

In the Siq of Petra, a robotic total station (LEICA TM 30), in reflector-less modality, was selected, to get the benefit of a high accuracy method as well as the largest capability to detect an analyze individual observation points selected by the rock mechanic specialists.

From a practical point of view, in any selected area one or more stations can be established. Such stations do not require precise permanent positions or ground markers, instead, a new highly precise position is determined for every new survey epoch, using a method referred to as Free-Station-Adjustment. This approach can be adopted if at least three permanently fixed prisms are visible from the Total Station set up point.

At present, more than 1600 individual points have been selected in potentially unstable areas of the Siq for reflector-less surveying. Figure 20 shows the point distribution in the treasury area.

\section{Traditional Geotechnical Monitoring in Wireless Environment}

The low environmental impact, even from a monitoring system, is a pre-requisite for any intervention in a high value cultural heritage site. 


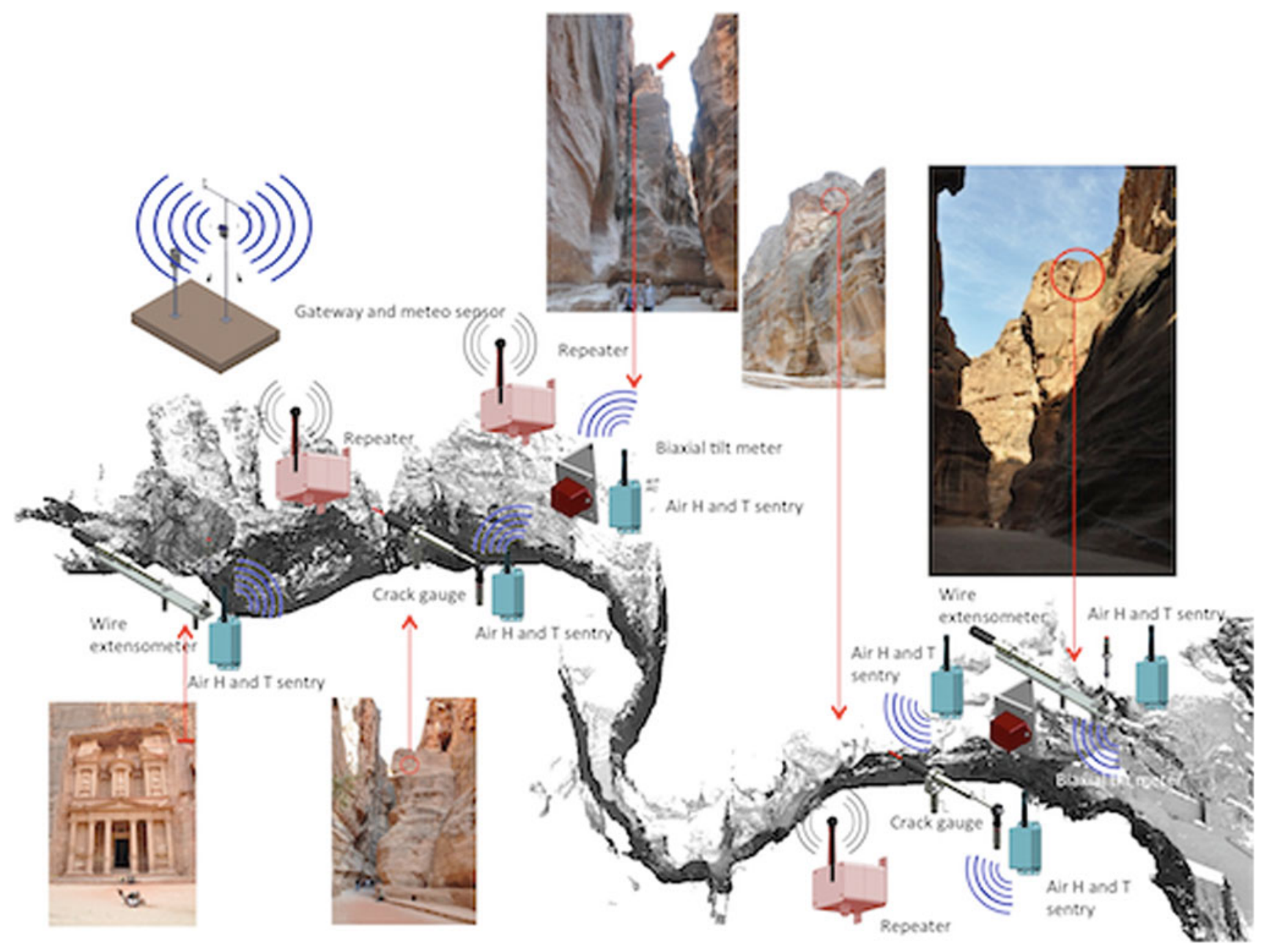

Fig. 21 Details of the geotechnical wireless monitoring network in the Siq of Petra (Jordan), superimposed on the 3D laser scanner of Siq

In order to define possible deformation paths and with the final aim to measure active displacement upon selected medium-large rock blocks affected by potential instability process, a proper permanent monitoring network was designed, implemented and installed along the entire Siq of Petra. The monitoring network (Fig. 21) consists of:

- n.2 tiltmeter sentries;

- $\mathrm{n} .2$ wire deformometer sentries;

- $\mathrm{n} .2$ crack meter/gauges sentries;

- n.6 air humidity and temperature sentries;

- n.1 meteorological station.

Geomechanical sentries are manufactured by Sisgeo and re-assembled by Minteos to provide longer duration measurement periods (about five years with four measurements per hour).

In order to solve the problem of the high visual impact of the monitoring network and related energy supplies and cables in the archaeological site of Petra, a wireless network equipped with long lasting batteries was designed, customized, implemented and installed. The present network ensures flexibility, remote control and future possibility to shift the system from monitoring to warning. The potentially unstable rock blocks were selected from the landslide inventory map, due to their potential hazard, size and typologies.

\section{Conservation Policies and Management}

Conservation of rupestrian sites is a complex endeavour, requiring expertise from the sciences of conservation, geotechnical engineering and earth science. On the other hand there is a high need for innovation addressing the central and exclusive role of conservators in the past and looking forward toward a truly holistic and interdisciplinary approach. In fact, measures to be adopted need to be as much as possible: 
(i) effective

(ii) non-invasive and

(iii) feasible for the employment of local materials and manpower.

The first requirement is obviously aimed at solving the problem; the second to emphasize the maximum preservation of the original aspect of the site, whereas the third is meant to maximize the reproducibility, both in time and space, of the adopted techniques in case of further interventions. The latter also includes the involvement of local community in protection and development of the site. This is not a minor point, since local expertise and traditional knowledge may enrich the sustainability of the conservation policies, ensuring local management and the long term maintenance.

Following are some examples of rupestrian sites where the above approach was pursued. Clearly, each case is unique, showing peculiar natural processes and social elements. As a consequence each site must be investigated with high attention to avoid the imposition of techniques and solutions that are not balanced in the specific cultural, natural and human environment, then balancing mitigation strategies with local expertise and traditional knowledge.

\section{Bamiyan (Afghanistan)}

The historical site of Bamiyan is affected by geomorphological deformation processes which were worsened by the explosion of the Buddhas in March 2001, which destroyed the statues that date back to the 6th century AD (Fig. 22). Not only was invaluable cultural heritage irremediably lost, but the consequences of the explosions as well as the collapse of the giant statues also added greatly to the geological instability of the area. Traces of rocks which recently slid and fell are relevant proofs of the deterioration of its stability conditions and most parts of the site now appear prone to collapse in the near future.

Under the coordination of UNESCO, a global project to assess the feasibility conditions for the site's restoration was developed (Margottini 2014a, b); field data were collected and a mechanism for the potential cliff and niches' evolution was provided. In the meantime some consolidation works were carried out in the most critical rock fall-prone areas, to avoid any further collapse in the coming winter season, but also to enable archaeologists to safely catalogue and recover the Buddha statues' remains, still lying on the floor of the niches. The emergency activities started in October 2003 and finished on 2012, and included:

- the installation of a monitoring system, to evaluate in real time any possible deformation of the cliff. Sensors were designed to monitor the entire working area, connected with an alarm system, to guarantee the safety of those working in the site;

- the realization of temporary protection with steel ropes, and two iron beams suitable to avoid lateral deformation, inside the niche, from blocks destabilized by the explosion. Among the temporary work, just after the consolidation of the niche's wall, a wire net was installed over the back wall of both niches to allow archaeologists to work on the ground floor in safe conditions;

- the final stabilization of the East niche. In this area anchors, nails and grouting were introduced (Fig. 20), in order to reduce the risk of rock fall and collapse; particular care was given to the problem of grouting material because of the very high slaking capability of siltstone. The anchors placed in 2003 were pre-grouted to avoid any oxidation and then percolated inside the niche. In 2004 it was decide to use only stainless steel materials, even if not pre-grouted.

- minimization of intervention (anchor/nail head finishing) complete the execution of work. Anchor and nail heads were designed to be placed slightly inside the rock and then covered by a mortar allowing a total camouflage of the work. A number of tests for the best mixture of cement, local clay/silt and water, used to cover the anchor/bolt heads, were also developed in 2003, in cooperation with ICOMOS experts. The results provided the best chromatic, stability and robustness of the mixture.

Some minor consolidation and impermeabilisation works were implemented in the Western Buddha niche in 2009.

Consolidation works were mainly implemented by professional climbers, directly operating on the cliff as well as by means of inner niche scaffolding (Fig. 23).

Finally, after the stabilization of the external part of the Eastern Buddha niche, in 2009-2012 the inner back wall (shear zone of explosion) was stabilized by means of small anchors and limited grouting also aimed at fixing the still existing original part of the Statue plaster, jointly executed by Engineering Geologists and Conservators (Fig. 24).

\section{Lalibela (Ethiopia)}

Lalibela is located in the northern-central part of Ethiopia. The town, which has a population of about twelve thousand, is situated at an altitude of $2600 \mathrm{~m}$ in the Lasta province of the Amhara region.

The construction of the eleven rock-hewn churches is attributed to King Lalibela (1167-1207) of the Zagwe dynasty. They are still in daily use for religious practices and ceremonies, and on important religious occasions large 

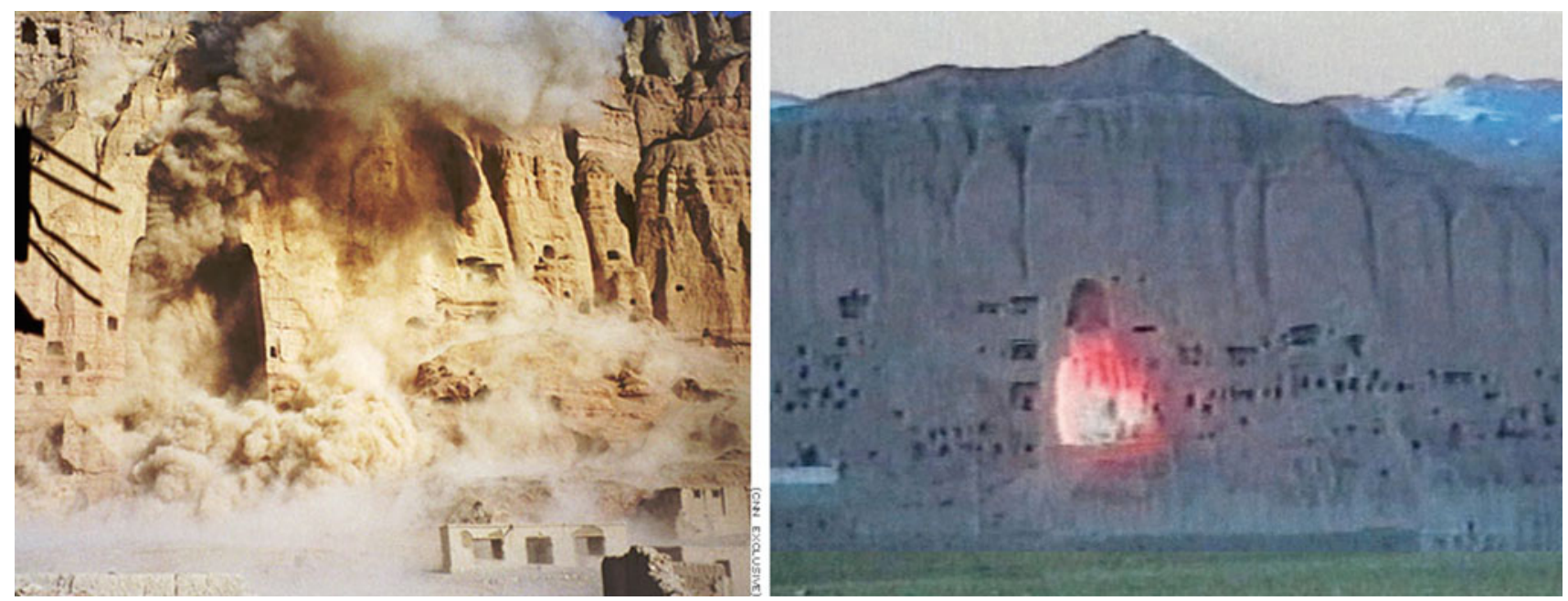

Fig. 22 Explosion and destruction of the Western (left) and Eastern (right) Giant Buddha Statues

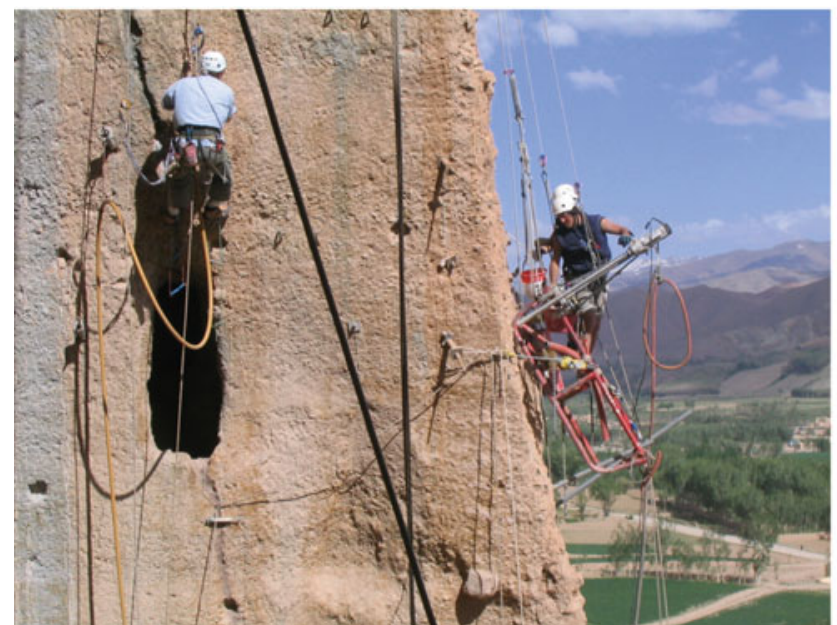

Fig. 23 Anchoring the Eastern Buddha niche (left) and pull-out tests for the use of $1 \mathrm{~m}$ length anchor in siltstone and conglomerate (right). The load $(\mathrm{kN})$ and respective time $(\mathrm{min})$ and elongation $(\mathrm{mm})$ are

crowds of believers and pilgrims gather at the site. The eleven churches and their surrounding area form a complex that is unique in the world. In 1978 the churches of Lalibela were included in UNESCO's World Heritage List.

The churches have been exposed to physical erosion for approximately eight hundred years. As a result, their condition has worsened over the years, and has now become critical. To protect the churches from direct exposure to the rain, five churches, namely Bete Medhane-Alem, Bete Maryam, Bete Masqal, Bete Amanuel and Bete Abba-Libanos, have been covered by temporary shelters.

The shelter design had to respect the following requirements:
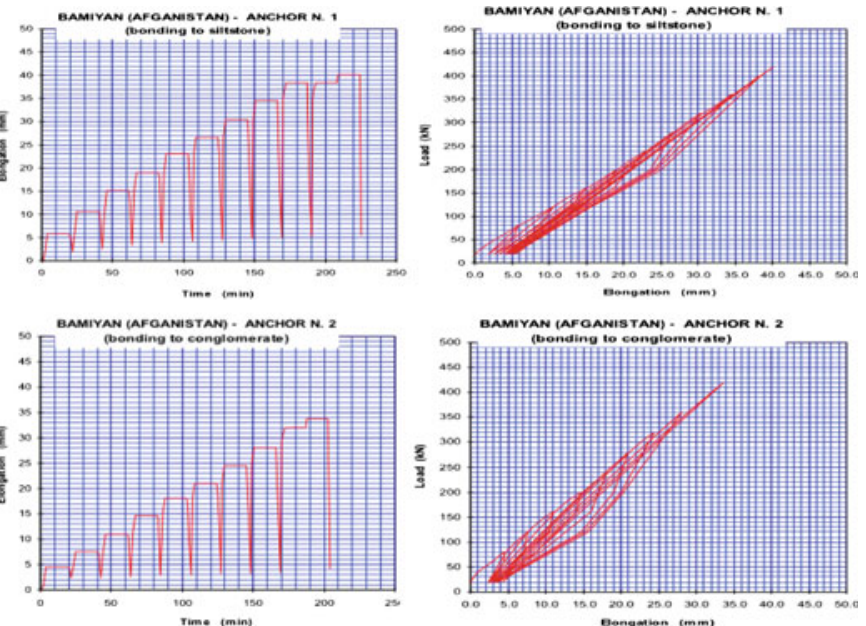

reported showing, till 40 ton, the uphold of elastic domain and still the missing of any permanent deformation for the tested anchors

- complete reversibility;

- perspiration;

- non alteration of the aesthetic qualities and absolute respect of the harmonic shape of the complex and of the texture and colours of the materials;

- to be implemented in a way to allow local management and maintenance.

As of this paper no proper investigation or restoration has been implemented. Only new shelters were introduced, but with an impact that was altering the aesthetic value of the site. Thus, the shelters are protected from water infiltration and can be considered as a temporary reliable 
Fig. 24 The scaffolding for the stabilisation of back wall shear zone and the position and typology of installed anchors (diam. $22 \mathrm{~mm}, 12 \mathrm{~mm}, 6 \mathrm{~mm}$ )
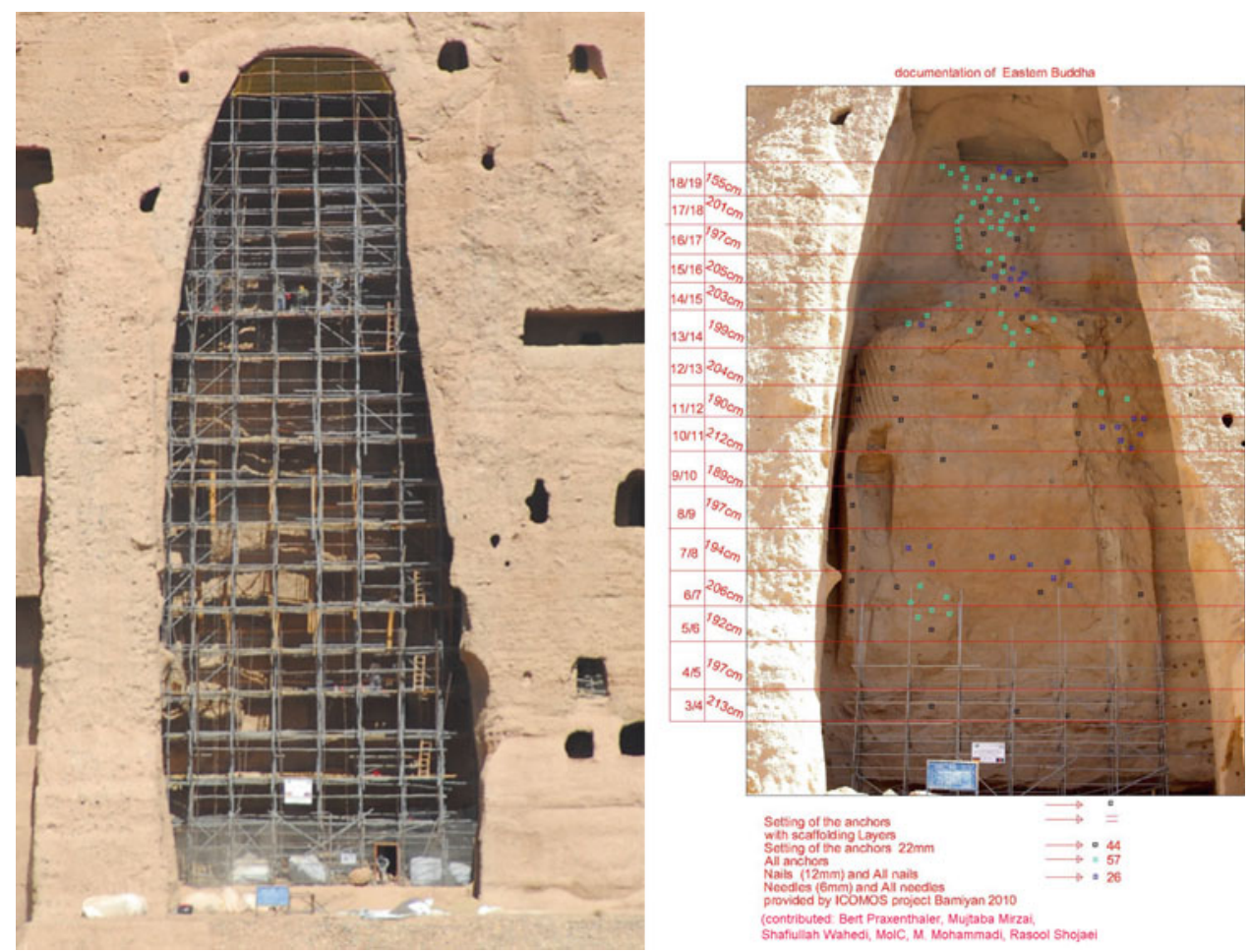

measurement before a correct conservation plan can be realized (Fig. 25).

\section{Petra (Jordan)}

The Siq of Petra is entirely formed of fractured rock slopes and potential detachment of rock materials represents possible hazard to people. Slope stability mitigation techniques are briefly described according to the materials involved, as well as typology and magnitude of potential failures in the Siq slopes, focusing on the most common and feasible typologies that can be successfully applied to the mitigation of landslides.

The selection of a specific mitigation typology for the stabilization of blocks/slopes in the Siq has to be done according to several basic conditions that take into account the following: volume of the unstable block; height of the block above the ground; potential impact on archaeological remains; local technical feasibility; and cost/benefit analysis.

Field geological and geo-structural investigation of potential rock slope failures conducted in the Siq have determined that failure modes affecting the rock masses of the Siq slopes can be classified into the following categories, according to the type and degree of structural control (kinematic movement): (i) Planar failures; (ii) Wedge failures; (iii) Toppling failures; (iv) Free fall; (v) Unstable loose blocks and debris.
According to the inventory map produced for the Siq Stability project (Margottini 2015), the volumes of potentially unstable rock blocks have been differentiated into 3 classes: (i) small blocks with volume $<5 \mathrm{~m}^{3}$; (ii) medium blocks with $5-15 \mathrm{~m}^{3}$ volume; and (iii) large blocks with volume $>15 \mathrm{~m}^{3}$.

Depending on typology and volume, several kinds of mitigation works have been suggested. In any case, such techniques cannot be applied without a local investigation on the site. In detail, the selection of potential working typologies has to take into account their impact on the peculiarity of the site geo-cultural environment (geomorphology, landslide types, presence of archaeological remains) so that only some specific typologies of consolidation interventions are recommended. Clearly, any intervention has to take into consideration the minimization of the environmental/visual impact of works, the local sustainability and feasibility, and the transfer of know-how to the local system. All these details are included in specific Guidelines (Margottini 2015) for the benefit of Jordanian authorities. Particular attention is given to the traditional techniques and the proper maintenance of such practices (Fig. 26).

\section{Norchia (Italy)}

The ancient Etruscan town of Norchia (Central Italy, $80 \mathrm{~km}$ North of Rome) is situated on a long volcanic plateau 


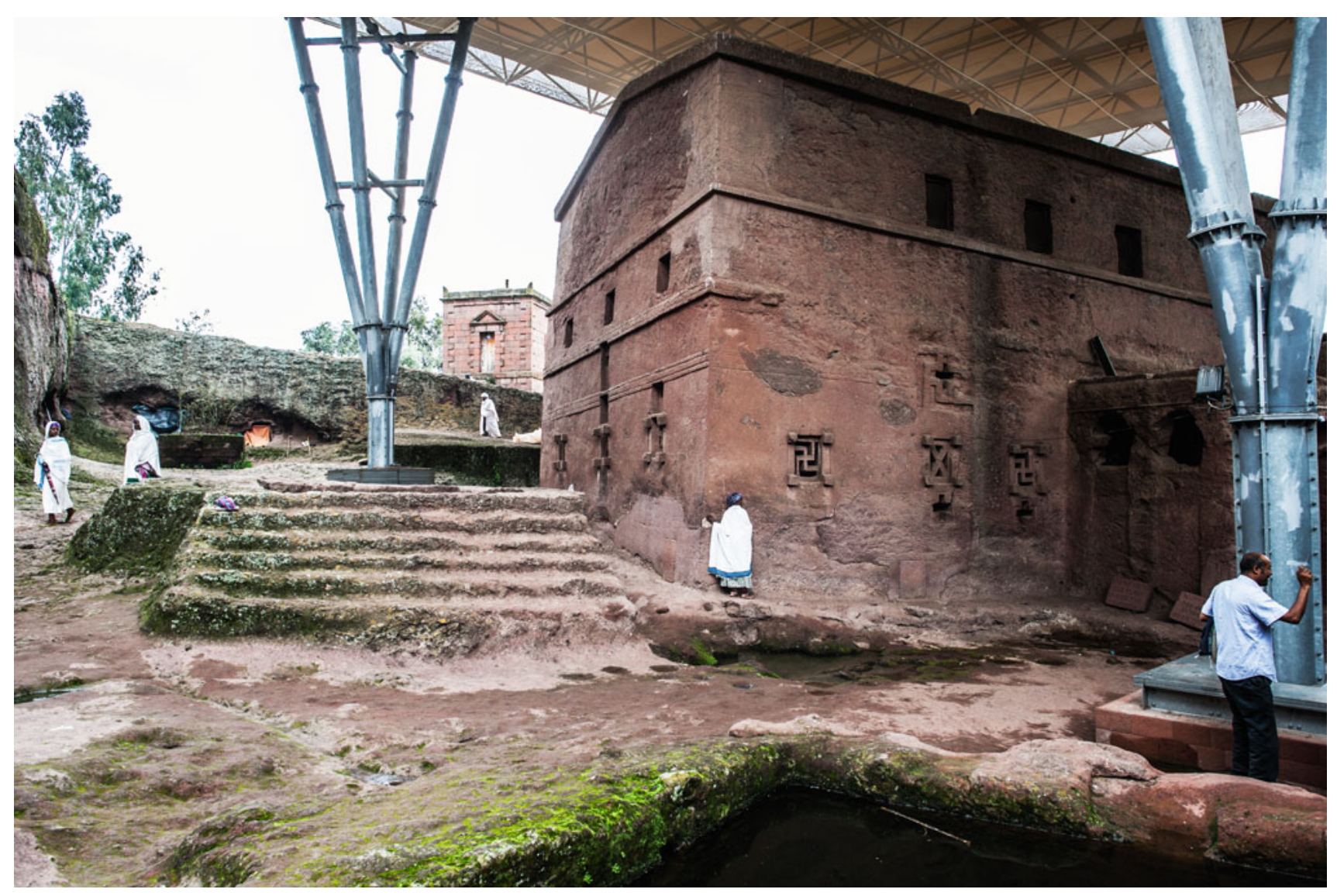

Fig. 25 The modern shelters covering the rock-hewn churches of Lalibela (Ethiopia) (source www.flickr.com)

surrounded by steep slopes, at the confluence of rivers Pile and Acqua Alta into the river Biedano. It has been constructed along the ancient Via Clodia, a short-range route intended for commercial traffic between Rome and the colonies in Etruscan lands.

The flourishing of the town, evidenced by the beautiful necropolis, is placed between the end of the fourth and half of the second century BC. With its necropolis Norchia is the most significant example of funerary architecture rock Hellenistic period (IV-II century BC.). Its rock-cut tombs are among the most important archaeological sites of Etruscan civilization. They are an important and rare example of rock architecture and one of the few preserved in Italy. Also, the necropolis, with an extension of more than 100 hectares, is composed of rock-cut tombs of various types (façade, half-cube, false-cube and temple type) and dimensions (4$10 \mathrm{~m}$ in height), exhibiting a remarkable similarity with Asian tombs. From a geological point of view, the area is exhibiting the overly rigid volcanic products from both Vico and Volsini volcanic apparatus; as bedrock, a plastic clay formation is positioned (Fig. 27).

The rock-cut tombs were excavated on two main volcanic levels, following the natural profile of tuff outcrops. The tombs located in the upper part of the necropolis have been excavated in a Red Tuff from Vico volcanic district, whereas those in lower level are dug into a grey tuff (Nenfro) from Vulsini volcanic apparatus. Recent investigations revealed the presence of many threats affecting the conservation of the site that include: surface rock weathering, water percolation and infiltration, surface vegetation and biological colonization, instability and collapse of the cliff. The purpose of this study was mainly focused to verify whether the geological, geomorphological and geomechanical processes that have allowed the creation of a typical "butte" landscape, later inhabited by Etruscans, are still active. Field survey and historical data collection revealed the presence of many rock slope instabilities that have affected the site. Particularly meaningful is the presence of a large debris fan, just at the toe 


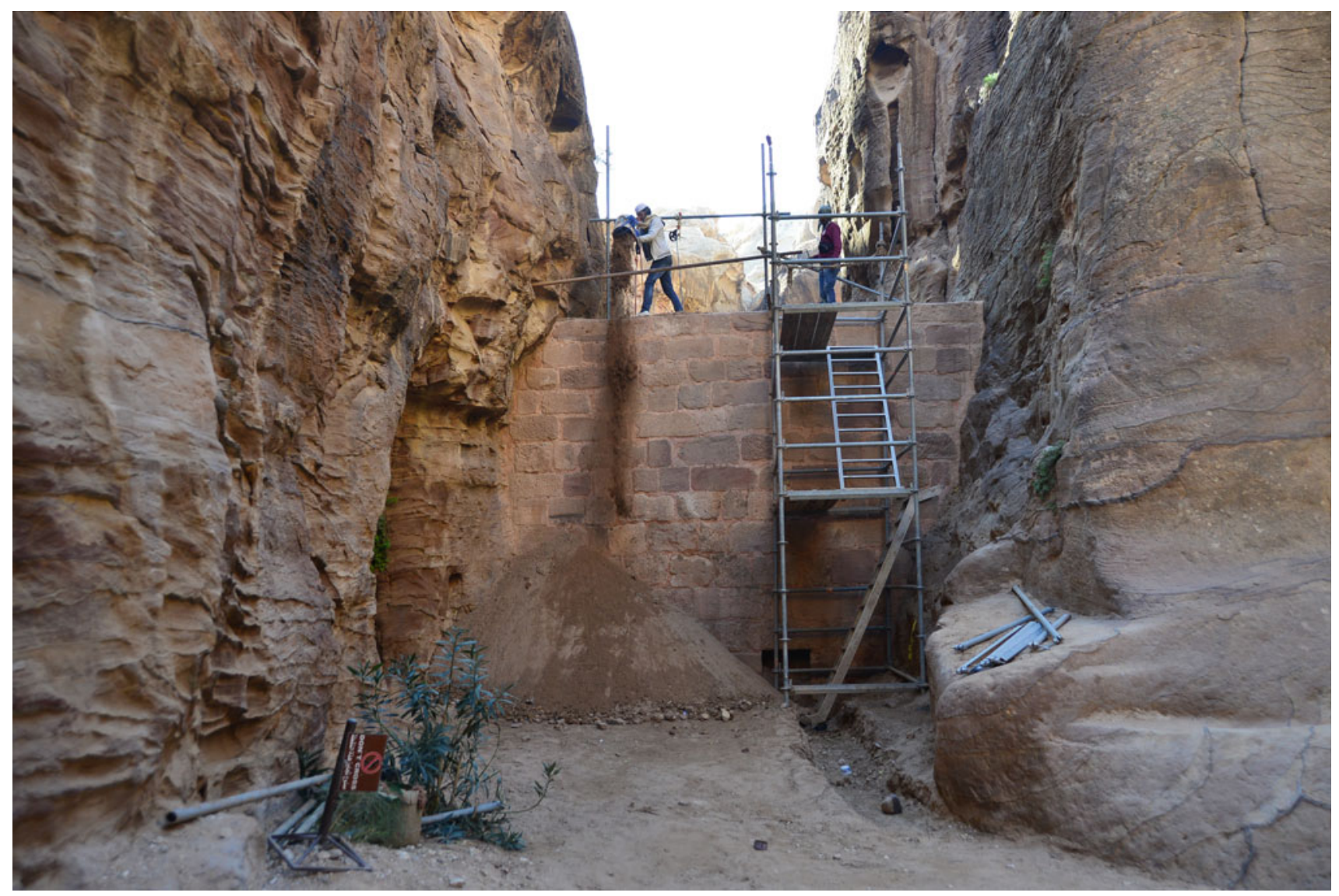

Fig. 26 Manual and proper cleaning of stone dams, to protect the Siq of Petra from flash flood

of the most relevant archaeological feature, where the half-cube rock-cut tombs are positioned, testifying to the importance of rock-falls after the excavation of the necropolis.

In recent periods such instabilities have been magnified by the weathering of the tuff and the growth of vegetation that is disconnecting original blocks.

The Necropolis is currently exhibiting a lack of maintenance. The preliminary investigation (Margottini et al. 2016a, b, c, d) revealed the need of stabilization of exposed rock cliff by means of anchor and dowels, as well as the reduction of water infiltration in existing joints and cracks. Such discontinuities have been probably generated by the stress release resulting in the formation of the valley and now widening as a consequence of vegetation. Eliminating vegetation in a very large area $(>10 \mathrm{Ha})$ is not an easy task. Indeed, in recent years the presence of farm animal (cows and sheep) highly reduced the growing of vegetation. In a situation of low budget availability, the implementation of a natural control system for vegetation through sheep and cow-farming was proposed by the local community. The latter can help to make the site more accessible to visitors and reduce the growth of vegetation affecting the slope stability. This maintenance solution, even if very trivial, can be implemented by means a public-private partnership, for the benefit a unique cultural heritage site, presently abandoned.

\section{Vardzia (Georgia)}

Vardzia represents an excellent example of a rock-cut city, which unites architectural monuments with an outstanding natural-geological environment. Such monuments are particularly vulnerable and their restoration and conservation requires a complex approach. The site is carved in various layers of volcanic tuffs and covers several hectares, with chronologically different segments of construction. This monument, as many similar monuments worldwide, is subjected to a slow but permanent process of destruction, through the following factors: surface weathering of rock, active tectonics (seismic displacement along the active faults and earthquakes), interaction between lithologically different rock layers, existence of major cracks and associated complex block structure, surface rainwater runoff and infiltrated 

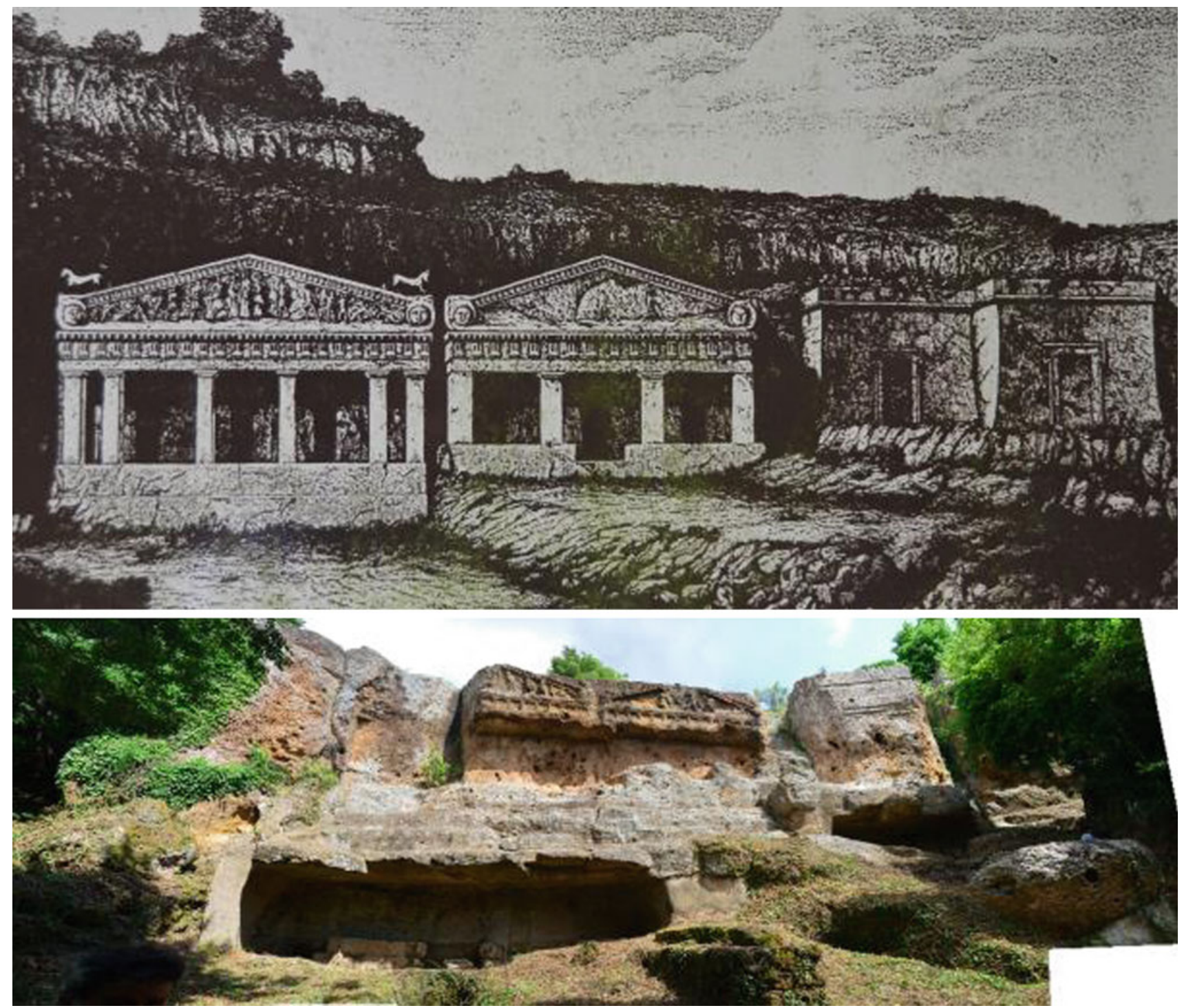

Fig. 27 The temple tombs of Norchia, as reconstructed form Canina (1851) and after the cleaning of vegetation in Spring 2016

ground water, temperature variations, etc. During its lifetime, Vardzia was heavily damaged by historical earthquakes, such as in 1283 , and only partly restored afterwards.

Currently there is major threat related to rock fall and rock slide (Margottini et al. 2015).

During the summer of 2015, after a joint collaboration with local Universities and Research Agencies, a first consolidation intervention was established. The mitigation project was based on an advanced monitoring system (Margottini et al. 2015) and the following field survey:

- Geomechanical rock mass classification through scan lines, in order to derive the main geomechanical characteristics and indexes (e.g. RMR, GSI);

- Tilt test;
- Schmidt-hammer test on joint surfaces and intact rock block for in situ analysis of UCS (unconfined compressive strength);

- Point load test to provide UCS data from sampled blocks (ISRM 1981, 1978);

- Strength and deformation parameters from scientific and technical literature (ISRM 1978; Hoeck 2007; Barton 1973) as well as from local technical reports;

- laboratory tests on tuff rock blocks and cores (Uniaxial and tensile strength parameters in dry and saturated conditions).

The main results are summarized in Table 2.

All the performed investigations allowed the definition of the most unstable areas. The map is reported in Fig. 29. 


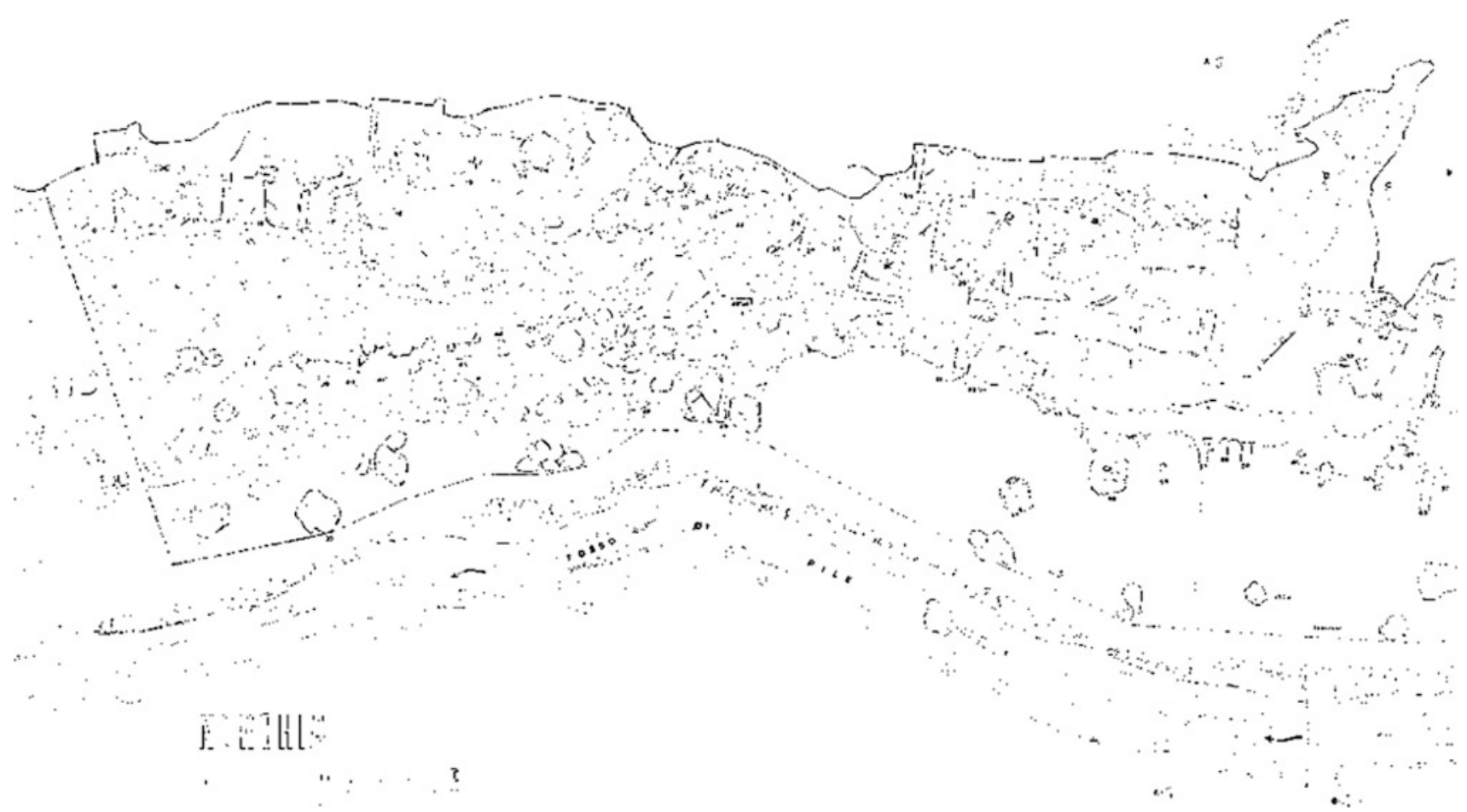

Fig. 28 Map of a large debris fan, just at the toe of the most relevant archaeological place, where the half-cube rock-cut tombs are positioned, testifying important rock-falls after the excavation of the necropolis (Colonna Di Paolo and Colonna 1978)

Table 2 Main geomechanical parameters of Vardzia rocks

\begin{tabular}{|c|c|c|c|c|c|c|c|c|}
\hline Lithology & $\begin{array}{l}\text { Unit weight } \gamma \\
(\mathrm{KN} / \mathrm{m} 3)\end{array}$ & $\begin{array}{l}\text { Porosity } \\
(\%)\end{array}$ & $\begin{array}{l}\sigma c \text { dry } \\
\mathrm{MPa}\end{array}$ & $\begin{array}{l}\sigma c \text { sat } \\
\mathrm{MPa}\end{array}$ & $\begin{array}{l}\text { Basic friction angle } \\
\left(\phi^{\circ}\right)\end{array}$ & GSI & $\begin{array}{l}\sigma t \text { dry } \\
\mathrm{MPa}\end{array}$ & $\begin{array}{l}\sigma \mathrm{t} \text { sat } \\
\mathrm{MPa}\end{array}$ \\
\hline Grey tuff & 16.3 & 37.2 & 10.3 & 3.6 & $22^{\circ}-32^{\circ}$ & 70 & 0.8 & 0.3 \\
\hline $\begin{array}{l}\text { White } \\
\text { tuff }\end{array}$ & 15.9 & 38.8 & 8.7 & 2.8 & $22^{\circ}-32^{\circ}$ & 65 & 0.9 & 0.3 \\
\hline
\end{tabular}

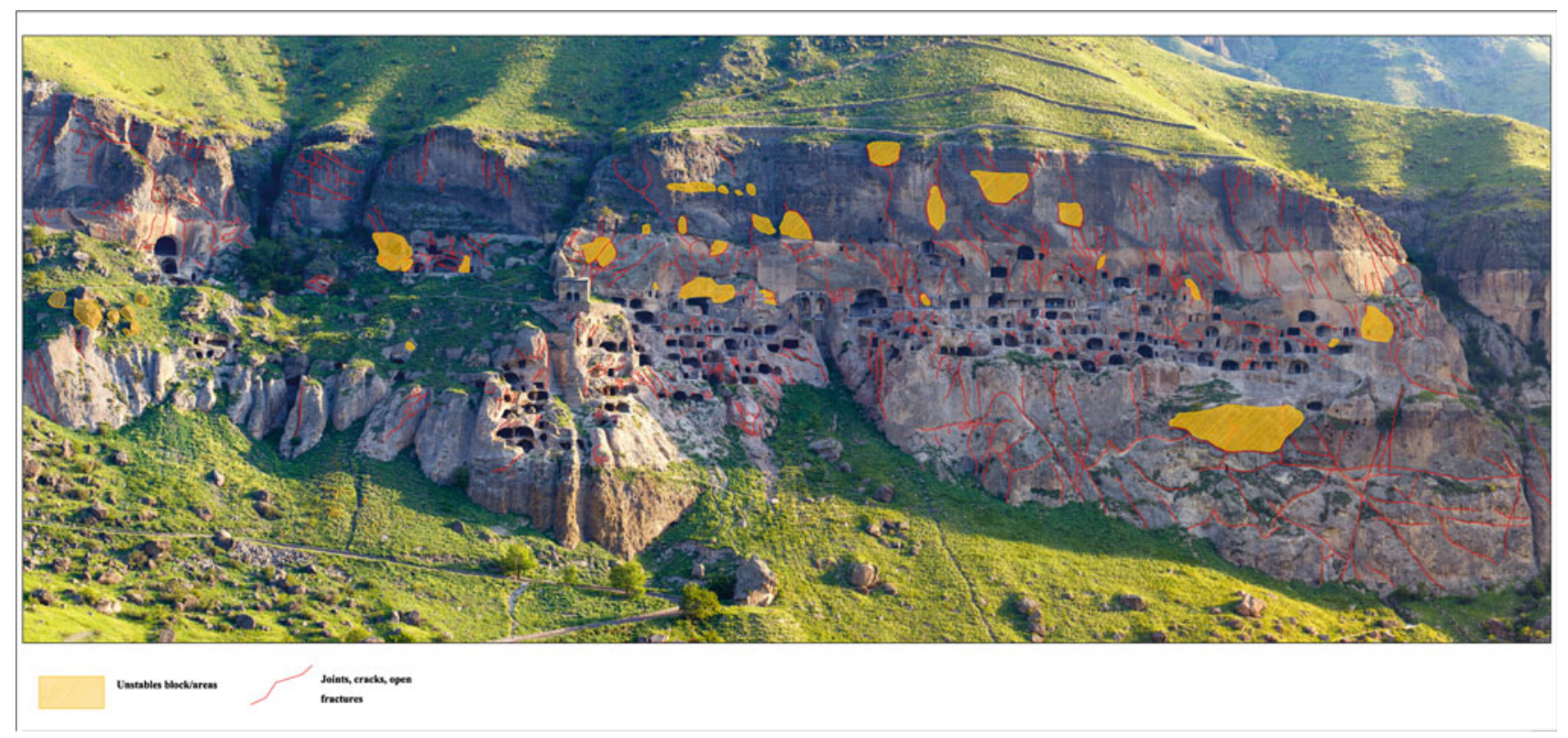

Fig. 29 Joints, cracks and unstable blocks in Vardzia cliff 
It was then decided to stabilize one of the potentially unstable blocks, located in the lower-right portion of Fig. 28, the largest among the selected ones. Such a block is also interesting because of the presence of an archaeological tunnel, connecting the flood plain with the rock-cut city.

The block, partially overhanging, is delimited on its back by a joint characterized by a high dip (on average $80^{\circ}$ ) and dip direction between $170^{\circ}$ and $178^{\circ}$. Its length is about $11.5 \mathrm{~m}$ along this section, whereas the area of the block is about $20.8 \mathrm{~m}^{2}$. The more likely failure mechanism, based on numerous in situ observations conducted along the cliff, is that of sliding along the joint previously described. This discontinuity is also characterized by a significant opening in some of its portions, highlighting the precarious stability conditions of the rock-mass under investigation.

The stability of the block was then evaluated adopting the limit equilibrium approach, with reference to possible sliding along the joint above described, together with the effectiveness of the proposed mitigation measurements consisting of passive rock dowels. The safety factor FS for the potential sliding can be expressed as:

$$
F S=\frac{C_{\text {rockbridges }}+N \tan \left(\varphi_{r}+J R C \log _{10} \frac{J C S}{\sigma_{n}}\right)}{T}
$$

where the symbol $\mathrm{C}_{\text {rock bridges }}$ indicates the strength contribution of the rock bridges potentially acting along the joint.

The final calculation was then elaborated, also taking into consideration the block reinforcement constituted by the installation of $32 \mathrm{~mm}$ diameter steel dowels, characterized by improved adherence, with reference to a Feb44 k concrete. The dowels should show a minimum characteristic yielding stress equal to $430 \mathrm{MPa}$, for a corresponding yielding load of $346 \mathrm{kN}$.

Unfortunately no experienced drilling company was available in Georgia, nor was a proper scaffolding for the site. It was then decided to initiate a large capacity building exercise of a local company contracted by the Agency for

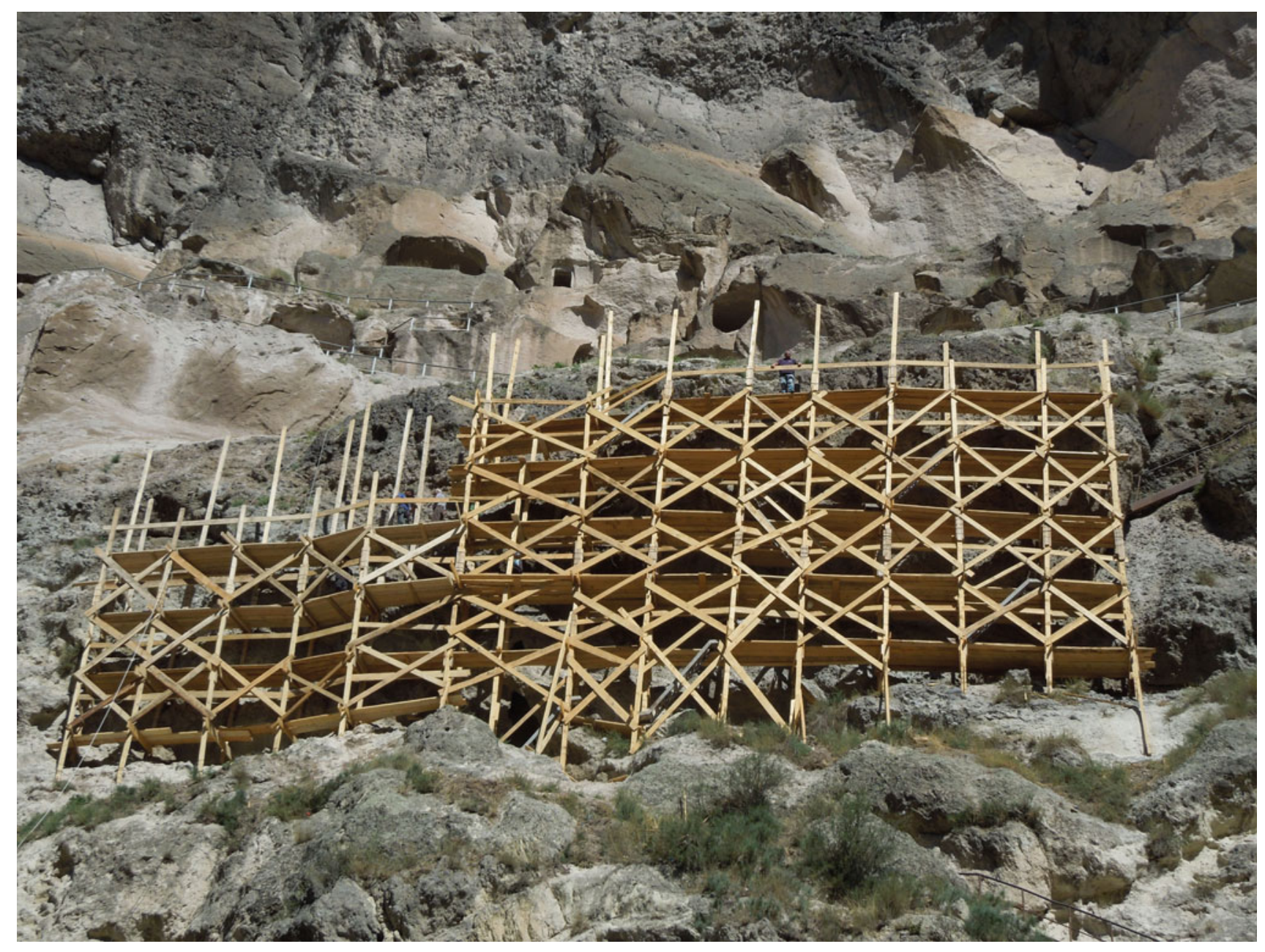

Fig. 30 The wood scaffolding realised in Vardzia 


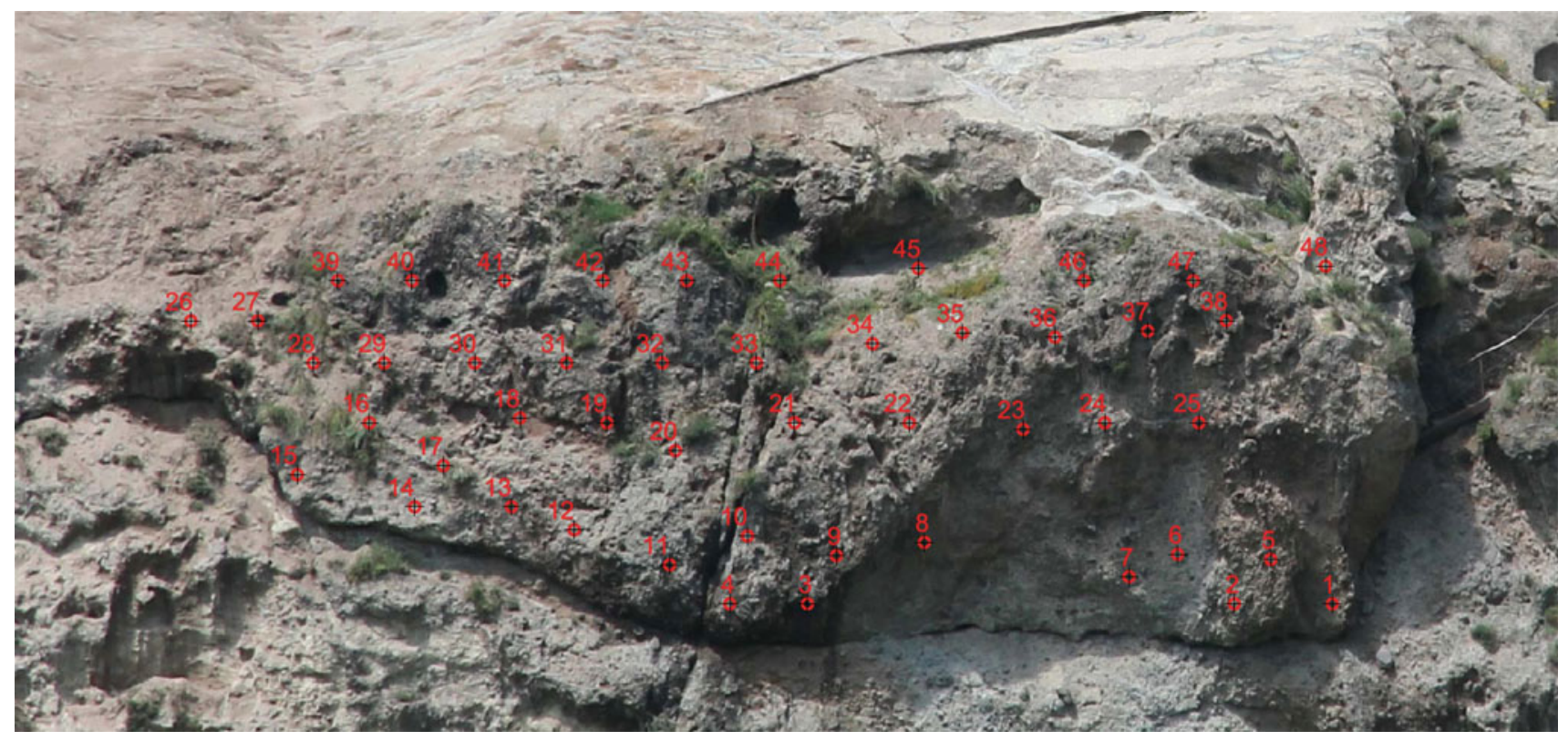

Fig. 31 Positioning of the the 48 installed dowels

Cultural Heritage Preservation of Georgia. An Italian engineer with considerable field work experience then accompanied the purchasing of equipment and the field work, including the construction of the scaffolding. The final successful result is shown in the following figure showing the realized wood scaffolding and the 48 installed dowels (Figs. 30 and 31).

\section{Conclusions}

The protection of rupestrian sites, from geotechnical and geological hazards is an interdisciplinary effort, involving, minimally, the Science of Conservation of Cultural Heritages and Earth Science. The conservator has to develop the proper restoration project, taking into consideration and having understood geological processes acting on the site and the monument; in the mean time, the engineering geologist has to implement a mitigation plan and monitoring system which fulfill the request for low impact and perfect integration of solutions into the archaeological contest. A typical example of connection points between these two major branches of science in heritage conservation, is the usage of solutions with low environmental impact, that cannot damage the site or the cultural landscape, while clearly reducing the natural processes acting on the site; similarly it is required to use materials that, over time, cannot loose original properties, generating salts, oxides, etc., that may affect the integrity and conservation of the heritage site. In this context also the proposed monitoring systems need to fulfill the requirement of low environmental impact and minimum interference with the archaeological remains.

The above reflections, without obviously being exhaustive, clearly underline the impact that the Earth Sciences have had in understanding and monitoring threats, as well as in the conservation of the cultural properties; it is self evident that the same disciplines have to assume, today and in the future, a fundamental role in all the policies that are necessary for the protection and conservation of the heritage.

This aspect of conservation has never been very clear in the past, since the archaeology and the conservation aspects had a strong centrality and autonomy. This point of view is now less evident, with more attention to the integration of different sciences. Indeed it is possible to affirm that the protection of cultural heritage represents an interdisciplinary process (and not multi-disciplinary) at the border of art, history, science, policies for management and exploitation.

The present paper demonstrates how the conservation of rupestrian sites requires an interdisciplinary approach, developing comprehensive field investigations and monitoring processes but, finally, implementing conservation practices and management of the sites that are based on local expertise and traditional knowledge. Clearly this paper does not report the comprehensive methodology, generally well known, but rather highlights the contribution of emerging technologies and interdisciplinary approaches to some specific issues. In this light, major recent achievements for application in cultural heritage, 
without being exhaustive, involve the following. In the field of basic data collection: laser scanning, new panorama photo utilization, mineralogy and petrography, rock mechanic parameters, semi-automatic discontinuities detection and analysis; kinematic analysis, infrared thermographic analysis. In the field of monitoring: ground based radar interferometry; reflector-less robotic surveying, laser scanning and traditional geotechnical monitoring in a wireless environment.

The collected data, jointly with traditional information mainly from rock mechanic and rock fall/slide investigation, allow the deep understanding of processes affecting a given site. The consequent mitigation strategy can then be prepared in order to ensure effectiveness of adopted solutions, non-invasive infrastructures and hopefully, feasible employment of local materials and manpower. Moreover, a proper understanding of local expertise joined with traditional and indigenous knowledge should address the proposed solutions in order to facilitate their execution and maintenance in time, and then, in other words, to enhance sustainability.

Acknowledgements The present paper was based on many interdisciplinary projects, mainly coordinated by UNESCO. The authors are very grateful to UNESCO colleagues and friends in Paris (WHC), Kabul and Amman, as well as to colleagues and friends of the National Agency for Cultural Heritage Preservation of Georgia.

\section{References}

Agustawijaya DS (2007) The uniaxial compressive strength of soft rock. Civ Eng Dimension 9(1):1, 9-14

Alberti S, Ferretti A, Margottini C, Spizzichino D (in printing) Surface deformation data in the archaeological site of Petra from mediumresolution satellite radar images. Submitted to J Cult Heritage

Bakun-Mazor D, Hatzor YH, Glaser SD, Santamarina JC (2011) Climatic effects on key-block motion: evidence from the rock slopes of Masada world heritage site. 45th US symposium in rock mechanics, San Francisco, California, pp 480-487

Bakun-Mazor D, Hatzor YH, Glaser SD, Santamarina JC (2013) Thermally versus seismically induced block displacements in Masada rock slopes. Intl J of Rock Mech and Ming Sci 61:196-211

Baroň I, Bečkovský D, Míča L (2014) Application of infrared thermography for mapping open fractures in deep-seated rockslides and unstable cliffs. Landslides 11:15-27

Barton NR (1973) Review of a new shear-strength criterion for rock joints. Eng Geol 7:287-332

Canina L (1851) Canina 1851: L'antica Etruria marittima, vol II Tavole, Roma

Casagli N, Gigli G (2011) Semi-automatic extraction of rock mass structural data from high resolution LIDAR point clouds. Int J Rock Mech Min Sci 48:187-198

Clark MR, McCann DM, Forde MC (2003) Application of infrared thermography to the non-destructive testing of concrete and masonry bridges. UK, NDT\&E International 36:265-275

Colonna Di Paolo E, Colonna G (1978) Norchia-Le necropoli rupestri dell'Etruria meridionale, vol 1 and 2, Roma
Dehn M, Bürger G, Buma J, Gasparetto P (2000) Impact of climate change on slope stability using expanded downscaling. Eng Geol 55:193-204

Delmonaco G, Margottini C (2014) General environmental conditions. In: Margottini C (ed) After the destruction of Giant Buddha statues in Bamiyan (Afghanistan) in 2001. A UNESCO's emergency activity for recovering and rehabilitation of cliff and niches. Springer-Verlag, Berlin Heidelberg, pp 69-100

Ercoli L, Megna B, Nocilla A, Zimbardo M (2013) Measure of a limestone weathering degree using laser scanner. Int $\mathrm{J}$ Architect Heritage 7:591-607

Fecker E (2006) Report on rock mechanical aspects concerning the Eastern Buddha Niche, ICOMOS Internal Report to UNESCO

Gigli G, Frodella W, Garfagnoli F, Morelli S, Mugnai F, Menna F, Casagli N (2013) 3-D geomechanical rock mass characterization for the evaluation of rockslide susceptibility scenarios. Landslides 1 : $1-14$

Gischig V, Moore J, Evans K, Amann F, Loew S (2011a) Thermomechanical forcing of deep rock slope deformation. 1. Conceptual study of a simplified slope. J of Geoph Res: Earth Surface, 116, F04010

Gischig V, Moore J, Evans K, Amann F, Loew S (2011b) Thermomechanical forcing of deep rock slope deformation. 2. The Randa rock slope instability. J of Geoph Res: Earth Surface, 116, F04011

Gomez-Heras M, Smith BJ, Fort R (2008) Influence of surface heterogeneities of building granite on its thermal microenvironment and its potential for the generation of thermal weathering. Environ Geol 56:547-560

Grøneng G, Christiansen H, Nilsen B, Blikra LH (2011) Meteorological effects on seasonal displacements of the Aknes rockslide, western Norway. Landslides 8:1-15

Gunzburger Y, Merrien-Soukatchoff V (2011) Near-surface temperatures and heat balance of bare outcrops exposed to solar radiation. Earth Surf Process and Land 36:1577-1589

Hales TC, Roering JJ (2007) Climate controls on frost cracking and implications for the evolution of bedrock landscapes. J. Geoph. Res-Earth Surf 112:1-14

Hatzor YH (2004) Keyblock stability in seismically active rock slopes the Snake Path cliff-Masada. J of Geotech and Geoenv Eng 129:697-710

Hoek E (2007) Practical rock engineering. http://www.rocscience.com. Access Sept 2015

Kasperski J, Delacourt C, Allemand P, Potherat P, Jaud M, Varrel E (2010) Application of a Terrestrial Laser Scanner (TLS) to the Study of the Séchilienne Landslide (Isère, France). Remote Sens 2:2785-2802

Krähenbühl R (2004) Temperatur und Kluftwasser als Ursachen von Felssturz. Bulletin fur angewandte Geologie 9:19-35

ISRM - International Society of Rock Mechanics - Commission On Standardization of Laboratory And Field Tests (1978) Suggested methods for the quantitative description of discontinuities in rock masses. Int J Rock Mech Min Sci Geomech Abs 15(6):319-368

ISRM - International Society of Rock Mechanics - Commission on the Classification of Rocks and Rock Masses (1981) Basic geotechnical description of rock masses. Int J Rock Mech Min Sci Geomech Abs 18:85-110

Lichun S, Wang X, Zhao D, Qu J (2008) Application of 3D laser scanner for monitoring of landslide hazards. Int Arch Photogrammetry, Remote Sens Spat Inf Sci 37:277-281

Mallet C, Bretar F (2009) Full-waveform topographic Lidar: Stateof-the-art. ISPRS J Photogrammetry and Remote Sens 64:1-16

Margottini C (ed) (2014) After the destruction of Giant Buddha statues in Bamiyan (AFghanistan) in 2001. A UNESCO's emergency activity for the recovering and rehabilitation of cliff and niches. Springer-Verlag, Berlin-Heidelberg 
Margottini C (2014) Properties of local materials. In: Margottini C (ed) After the destruction of Giant Buddha statues in Bamiyan (Afghanistan) in 2001. A UNESCO's emergency activity for recovering and rehabilitation of cliff and niches. Springer-Verlag, Berlin Heidelberg, pp 153-171

Margottini C (ed) (2015) Guidelines for the sustainable mitigation and management of landslides at the Siq-Petra World Heritage Site. ISPRA Internal Report to UNESCO-Draft

Margottini C, Antidze N, Corominas J, Crosta GB, Frattini P, Gigli G, Giordan D, Iwasaky I, Lollino G, Manconi A, Marinos P, Scavia C, Sonnessa A, Spizzichino D, Vacheisvili N (2015) Landslide hazard assessment, monitoring and conservation of Vardzia Byzantine monastery complex, Georgia. Landslides 12:193-204

Margottini C, Gigli G, Ruther H, Spizzichino D (2016a) Advances in geotechnical investigations and monitoring in rupestrian settlements inscribed in the UNESCO's World Heritage List. In: Proceedings of the fourth Italian workshop on landslides, Procedia, Elsevier

Margottini C, Gigli G, Ruther H, Spizzichino D (2016b) Advances in sustainable conservation practices in rupestrian settlements inscribed in the UNESCO's World Heritage List. In: Proceedings of the fourth Italian workshop on landslides, Procedia, Elsevier

Margottini C, Spizzichino D (2014) How geology shapes human settlements. In: Bandarin F, van Oers R (eds) (2014) Reconnecting the city. The historic urban landscape approach and the future of Urban Heritage. Wiley Blackwell, Chichester, pp 47-84

Margottini C, Spizzichino D, Argento A, Russo A (2016) Rock-fall hazard in the Etruscan archaeological site of Norchia (Central Italy). Geophys Res Abstracts 18:14434 (EGU General Assembly 2016)

Margottini C, Spizzichino D, Crosta GB, Frattini P, Mazzanti P, Scarascia Mugnozza G, Beninati L (2016d) Rock fall instabilities and safety of visitors in the historic rock cut monastery of Vardzia (Georgia). In: Rotonda T, Cecconi M, Silvestri F, Tommasi P (eds) Volcanic rocks and soils. CRC Press Balkema, Taylor and Francis Group, pp 371-378

Metzger R, Jaboyedoff M, Oppikofer T, Viero A, Galgaro A (2009) Coltop3D: a new software for structural analysis with high resolution 3D point clouds and DEM. AAPG Search and Discovery Article \#90171 CSPG/CSEG/CWLS GeoConvention 2009, Calgary, Alberta, Canada, 4-8 May 2009

Oppikofer T, Jaboyedoff M, Pedrazzini A, Derron MH, Blikra LH (2011) Detailed DEM analysis of a rockslide scar to characterize the basal sliding surface of active rockslides. J Geophys Res 116:1-22
Pirotti F, Guarnieri A, Vettore A (2013) Ground filtering and vegetation mapping using multi-return terrestrial laser scanning. ISPRS J Photogrammetry and Remote Sens 76:56-63

Pasten C, García M, Cortes DD (2015) Physical and numerical modelling of the thermally induced wedging mechanism. Geotechnique Lett 5(3):186-190

Renzulli A, Antonelli F, Margottini C, Santi P, Fratini F (2011) What kind of volcanite the rock-hewn churches of the Lalibela UNESCO's world heritage site are made of? J Cult Heritage 12:227-235

Rüther H (2015) Surface model of the Siq. In: Margottini C (ed) Guidelines for the sustainable mitigation and management of landslides at the Siq-Petra World Heritage Site. ISPRA Internal Report to UNESCO-Draft, pp 7-11

Rüther H, Bhurtha R, Wessels S (2014) Spatial documentation of the Petra World Heritage Site. Africa Geo 1

Stiros SC, Vichas C, Skourtis C (2004) Landslide monitoring based on geodetically derived distance changes, J Surv Eng-ASCE, 130 (4):156-162

Tsai Z, You GJY, Lee HY, Chiu YJ (2012) Use of a total station to monitor post-failure sediment yields in landslide sites of the Shihmen reservoir watershed. Geomorphology 139-140:438-451

Vargas JR, Castro JT, Amaral C, Figueiredo RP (2004) On mechanism for failure of some rock slopes in Rio de Janeiro, Brasil: thermal fatigue? In: Lacerda WA, Ehrlich M, Fontoura SAB, Sayao ASF (eds) Proc of 9th Int Symp on Landslides. Rio de Janeiro, Brazil, pp 1007-1013

Varnes DJ (1978) Slope movement types and processes. In: Schuster RL, Krizek RJ (eds) Landslides, analysis and control. Transportation research board Sp. Rep. No. 176, Nat Acad of Sciences, pp 11-33

Vlcko J, Greif V, Grof V, Jezny M, Petro L, Brcek M (2009) Rock displacement and thermal expansion study at historic heritage sites in Slovakia. Environ Geol 58:1727-1740

Wunderlich T (2006) Geodätisches Monitoring_Ein fruchtbares Feld für interdisziplinäre Zusammen-arbeit. Vermessung \& Geoinformation $1+2: 50-62$

Vlcko J, Jezny M, Pagacova Z (2005) Influence of thermal expansion on slope displacements. In: Sassa K, Fukuoka H, Wang F, Wang G (eds) Proceedings of the first general assembly of the international consortium on landslides. Landslides: Risk Analysis and Sustainable Disaster Management. Springer Verlag, Washington
Open Access This chapter is licensed under the terms of the Creative Commons Attribution 4.0 International License (http:// creativecommons.org/licenses/by/4.0/), which permits use, sharing, adaptation, distribution and reproduction in any medium or format, as long as you give appropriate credit to the original author(s) and the source, provide a link to the Creative Commons license and indicate if changes were made.
The images or other third party material in this chapter are included in the chapter's Creative Commons license, unless indicated otherwise in a credit line to the material. If material is not included in the chapter's Creative Commons license and your intended use is not permitted by statutory regulation or exceeds the permitted use, you will need to obtain permission directly from the copyright holder. 